\title{
Reactions during melting of low-activity waste glasses and their effects on the retention of rhenium as a surrogate for technetium-99
}

\author{
Tongan Jin, ${ }^{\mathrm{a}}$ Dongsang Kim, ${ }^{\mathrm{a}, 1}$ Abigail E. Tucker, ${ }^{\mathrm{a}}$ Michael J. Schweiger, ${ }^{\mathrm{a}}$ and \\ Albert A. Kruger ${ }^{\mathrm{b}}$
}

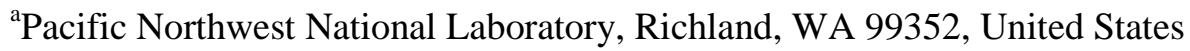

${ }^{\mathrm{b}}$ U.S. Department of Energy, Office of River Protection, Richland, WA 99352, United States

\begin{abstract}
Volatile loss of radioactive technetium-99 $\left({ }^{99} \mathrm{Tc}\right)$ to off-gas is a major challenge when vitrifying low-activity waste (LAW) at the U.S. Department of Energy's Hanford Site in Washington State. We investigated the partitioning and incorporation of rhenium $(\mathrm{Re})$ (a nonradioactive surrogate for ${ }^{99} \mathrm{Tc}$ ) into the glass melt during crucible melting of two simulated LAW feeds that have exhibited a large difference in ${ }^{99 \mathrm{~m}} \mathrm{Tc} / \mathrm{Re}$ retention in glass from small-scale melter tests. Each feed was prepared from a simulated liquid LAW and additives (boric acid, silica sand, etc.). The as-mixed slurry feeds were dried at $105^{\circ} \mathrm{C}$ and heated to $600-1100^{\circ} \mathrm{C}$ at $5 \mathrm{~K} / \mathrm{min}$. The dried feeds and heat-treated samples were leached with deionized water for $10 \mathrm{~min}$ at room temperature followed by $24-\mathrm{h}$ leaching at $80^{\circ} \mathrm{C}$. Chemical compositions of the resulting solutions and insoluble solids were analyzed. Volume expansion measurements and X-ray diffraction (XRD) analyses were performed on dried feeds and heat-treated samples to characterize the progress of feed-to-glass conversion reactions. We found that incorporation of Re into the glass melt was virtually completed during the major feed-to-glass conversion reactions that occurred at $\leq 700^{\circ} \mathrm{C}$. The results of our study suggest that the different compositions of the salt phases
\end{abstract}

\footnotetext{
${ }^{1}$ Corresponding author. Tel: +1 (509) 372-4611; Fax: +1 (509) 372-5997; E-mail: dongsang.kim@pnnl.gov
} 
formed during early stages of melting at $\leq 700^{\circ} \mathrm{C}$ are responsible for the large difference in $\mathrm{Re}$ incorporation into the glass melt in these two feeds.

Keywords: low-activity waste; borosilicate glass; technetium; rhenium; volatilization

\subsection{Introduction}

Approximately $210,000 \mathrm{~m}^{3}$ of radioactive and chemically hazardous wastes, which are byproducts of approximately 45 years of plutonium production, is currently stored in underground tanks at the U.S. Department of Energy's Hanford Site in Washington State. The current cleanup plan is to separate the tank wastes into high-volume, low-activity waste (LAW) and low-volume, high-level waste (HLW) fractions that will then be vitrified into separate glass waste forms for long-term storage [1-3]. The LAW, a processed aqueous solution from tanks, primarily consists of sodium nitrates and nitrites with other salts/hydroxides and organics that vary from tank to tank (see an example composition given in Schonewill et al. [4]). Vitrifying the large amount of the LAW is one of the primary missions of the Hanford Tank Waste Treatment and Immobilization Plant (WTP) that currently is under construction. To immobilize the hazardous waste into a stable glass waste form, the LAW will be mixed with specifically designed glass-forming and modifying additives consisting of silica, boric acid, and other chemicals/minerals, and the mixture then will be vitrified.

One of the main radionuclides of concern in Hanford LAW is technetium-99 $\left({ }^{99} \mathrm{Tc}\right)$ [5-7]. The environmental concern with ${ }^{99} \mathrm{Tc}$ is its high mobility in subsurface soils and long half-life $\left(2.1 \times 10^{5} \mathrm{y}\right)$. The highly soluble $\mathrm{TcO}_{4}{ }^{-}$does not adsorb well onto the surface of minerals [8-10] and, thus, migrates nearly at the same velocity as groundwater [11]. More importantly, the primary concern with processing the ${ }^{99} \mathrm{Tc}$-containing waste into a glass is its extreme volatility, which results in low concentrations of Tc retained in the final product relative to target concentrations [12-16]. Recent small-scale melter tests with seven representative Hanford LAW glass feeds (simulated waste plus additives) for the WTP showed that the fraction of technetium retained in glass (referred to as retention) varied from $18 \%$ to $66 \%$ depending 
on the feed composition [12-14]. Although the volatilized ${ }^{99} \mathrm{Tc}$ can be captured in the off-gas treatment system and recycled to the melter to increase the retention, the recycle stream also contains other volatile components such as sulfur $(\mathrm{S})$, chlorine $(\mathrm{Cl})$, and fluorine $(\mathrm{F})$ that decrease the loading of waste in the glass [17] and, thus, increase the glass volume. Maximizing the incorporation of ${ }^{99} \mathrm{Tc}$ into glass is desirable also to minimize the fraction that needs to be treated as a secondary waste and disposed in nonglassy waste forms $[18,19]$.

Rhenium (Re) has been the preferred nonradioactive ${ }^{99} \mathrm{Tc}$ surrogate because of the similarities of Re to ${ }^{99} \mathrm{Tc}$ in chemistry, ionic size, speciation in glass, and volatility in glass [20]. It is known that Re and ${ }^{99} \mathrm{Tc}$ behave differently when redox reactions are involved because of the differences in reduction potentials of $\operatorname{Re}^{7+}$ and $\mathrm{Tc}^{7+}[21-24]$, yet the chemistry of the two elements is similar when in the same oxidation state. Kim et al. [21] investigated the behavior of ${ }^{99} \mathrm{Tc}$ and Re during crucible melting of simulated Hanford LAW glass feeds designed for bulk vitrification technology demonstration. For the two feed compositions treated without reducing agents, ${ }^{99} \mathrm{Tc}$ and Re showed the same trends for partitioning into salt phase, volatilization during melting, and retention in glass. However, for the two feeds modified to provide reducing conditions, ${ }^{99} \mathrm{Tc}$ and $\mathrm{Re}$ showed different reaction characteristics resulting in higher retention of ${ }^{99} \mathrm{Tc}$ in glass than $\mathrm{Re}$, which confirmed that Re is not a suitable surrogate for ${ }^{99} \mathrm{Tc}$ when redox reactions are involved. The small-scale, Joule-heated melter tests by Matlack and coworkers [12-14] showed a similar trend for the retention of ${ }^{99 \mathrm{~m}} \mathrm{Tc}$ (a short-lived technetium isotope as a surrogate of ${ }^{99} \mathrm{Tc}$ ) and Re in the seven representative Hanford LAW glasses they processed.

Previous studies $[25,26]$ employed a vacuum-sealed fused silica ampoule setup to measure the solubility of Re and ${ }^{99} \mathrm{Tc}$ in a representative LAW glass. The measured solubility was $3000 \mathrm{ppm}$ mass for Re (used as surrogate for Tc) [25] and 2000-2800 ppm mass for ${ }^{99} \mathrm{Tc}$ [26] (both on metal basis) at $1000^{\circ} \mathrm{C}$. Given the projected concentration of ${ }^{99} \mathrm{Tc}$ in LAW glass at Hanford is $\sim 3 \mathrm{ppm}$ mass on average [26]; the solubility of ${ }^{99} \mathrm{Tc}$ is not a factor in its retention in LAW glass. In addition, the structural role of Re and Tc in glass network was discussed in Goel et al. 2013 [27] and Gassman et al. 2014 [28]. 
A series of studies is being performed to understand the mechanism of Re/Tc escape from, or incorporation into, the glass melt during melting of Hanford LAW glass feeds. The goal is to eventually develop methods that will increase ${ }^{99}$ Tc retention. Two simulated melter feeds (AN-102 and AZ-102) that showed a large difference in Re and ${ }^{99 \mathrm{~m}} \mathrm{Tc}$ retention in glass from the small-scale melter tests [12-14] were selected for the initial studies. The AN-102 feed showed a ${ }^{99 \mathrm{~m}} \mathrm{Tc}$ retention of $19 \%$ and a Re retention of $27 \%$, while the AZ-102 feed showed a ${ }^{99 \mathrm{~m}} \mathrm{Tc}$ retention of $66 \%$ and a Re retention of $57 \%$. The objective of this study is to identify the major factors that differentiate Re/Tc retention between these two feeds.

Our study focuses on the details of Re (used as a surrogate for ${ }^{99} \mathrm{Tc}$ ) behavior during crucible melting of the melter feeds under oxidizing conditions (i.e., without addition of reducing agents) so that Re can be reasonably used as a surrogate for ${ }^{99} \mathrm{Tc}$. The two selected LAW glass feeds were heat treated in an open crucible to investigate the partitioning and distribution of Re as a function of temperature. A three-step leaching of heat-treated samples was performed to separate the water soluble phases from the unreacted mineral and glass-forming phases (insoluble). Information on the Re partitioning into different phases and Re retention in glass was obtained by chemical analyses of leach solutions and remaining insoluble solids. To evaluate the effect of feed melting reactions on the Re partitioning or distribution, the two selected feeds also were characterized for mass change, volume change, and crystalline phase evolution as a function of temperature using the techniques previously applied for feed melting studies [29-34].

\subsection{Materials and methods}

\subsection{Composition of simulated waste glass feeds}

The compositions of simulated waste and additives for the AN-102 and AZ-102 glass feeds are shown in Table 1. These compositions were obtained by modifying melter feeds used in the small-scale melter tests by Matlack et al. [13-14] based on the purity and composition of the chemicals and minerals 
used in this study. AN-102 is a high-nitrate, medium-sulfate waste, and AZ-102 is a low-nitrate, highsulfate waste. The LAW glasses designed to immobilize the wastes were correspondingly named as AN102 glass (designated as LAWE7H by Matlack et al. [13-14]) and AZ-102 glass (LAWE10H) for convenience. The target Re concentration in both glasses is $8.1 \mathrm{ppm}$ (mass fraction, as Re metal), a molar equivalent to $4.3 \mathrm{ppm}{ }^{99} \mathrm{Tc}$, which was used in a previous study [21] as a typical ${ }^{99} \mathrm{Tc}$ concentration in Hanford LAW glasses.

Table 1. Compositions of AN-102 and AZ-102 melter feeds for $1 \mathrm{~L}$ of simulated waste [14].

\begin{tabular}{|c|c|c|}
\hline Component & AN-102 & AZ-102 \\
\hline \multicolumn{3}{|l|}{ Simulated LAW (g/L) } \\
\hline $\mathrm{Al}\left(\mathrm{NO}_{3}\right)_{3} \cdot 9 \mathrm{H}_{2} \mathrm{O}$ & 87.97 & 1.75 \\
\hline $\mathrm{H}_{3} \mathrm{BO}_{3}$ & 0.10 & - \\
\hline $\mathrm{Ca}\left(\mathrm{NO}_{3}\right)_{2} \cdot 4 \mathrm{H}_{2} \mathrm{O}$ & 1.46 & - \\
\hline $\mathrm{Na}_{2} \mathrm{CrO}_{4} \cdot 4 \mathrm{H}_{2} \mathrm{O}$ & 2.76 & 3.46 \\
\hline $\mathrm{KOH}$ & 7.38 & 9.21 \\
\hline $\mathrm{NaOH}$ & 52.88 & 3.16 \\
\hline $\mathrm{NiO}$ & 0.09 & 0.11 \\
\hline $\mathrm{PbO}$ & 0.09 & 0.11 \\
\hline $\mathrm{SiO}_{2}$ & 0.10 & 0.37 \\
\hline $\mathrm{NaCl}$ & 3.72 & 4.65 \\
\hline $\mathrm{NaF}$ & 1.97 & 2.46 \\
\hline $\mathrm{Na}_{3} \mathrm{PO}_{4} \cdot 12 \mathrm{H}_{2} \mathrm{O}$ & 7.56 & 9.39 \\
\hline $\mathrm{Na}_{2} \mathrm{SO}_{4}$ & 12.07 & 20.32 \\
\hline $\mathrm{NaNO}_{2}$ & 64.80 & 35.51 \\
\hline $\mathrm{NaNO}_{3}$ & 94.65 & 9.68 \\
\hline $\mathrm{Na}_{2} \mathrm{CO}_{3}$ & 49.21 & 40.97 \\
\hline Sodium Formate $\left(\mathrm{NaHCO}_{2}\right)$ & 24.90 & - \\
\hline Sodium Oxalate $\left(\mathrm{Na}_{2} \mathrm{C}_{2} \mathrm{O}_{4}\right)$ & 1.44 & - \\
\hline Glycolate $\left(\mathrm{C}_{2} \mathrm{H}_{4} \mathrm{O}_{3}\right)$ & 30.60 & - \\
\hline Citric Acid $\left(\mathrm{C}_{6} \mathrm{H}_{8} \mathrm{O}_{7}\right)$ & 8.98 & - \\
\hline Oxalic Acid $\left(\mathrm{C}_{2} \mathrm{H}_{2} \mathrm{O}_{4} \cdot 2 \mathrm{H}_{2} \mathrm{O}\right)$ & - & 3.21 \\
\hline $\mathrm{Re}_{2} \mathrm{O}_{7}$ & 0.0121 & 0.0151 \\
\hline Water (estimated) & 792.96 & 975.01 \\
\hline \multicolumn{3}{|c|}{ Additives (g/L simulated waste) ${ }^{\mathrm{a}}$} \\
\hline Kyanite $\left(\mathrm{Al}_{2} \mathrm{SiO}_{5}\right)$ & 98.73 & 149.71 \\
\hline $\mathrm{H}_{3} \mathrm{BO}_{3}$ & 200.58 & 252.97 \\
\hline Wollanstonite $\left(\mathrm{CaSiO}_{3}\right)$ & 155.51 & 215.41 \\
\hline Hematite $\left(\mathrm{Fe}_{2} \mathrm{O}_{3}\right)$ & 59.46 & 71.71 \\
\hline
\end{tabular}




\begin{tabular}{|c|c|c|}
\hline $\mathrm{Li}_{2} \mathrm{CO}_{3}$ & 89.87 & 150.93 \\
\hline Olivine $\left(\mathrm{Mg}_{2} \mathrm{SiO}_{4}\right)$ & 35.54 & 87.65 \\
\hline $\mathrm{Na}_{2} \mathrm{CO}_{3}$ & - & 34.02 \\
\hline Quartz $\left(\mathrm{SiO}_{2}\right)$ & 362.31 & 472.28 \\
\hline Rutile $\left(\mathrm{TiO}_{2}\right)$ & 15.22 & 18.82 \\
\hline Zincite ( $\mathrm{ZnO})$ & 39.63 & 49.81 \\
\hline Zircon $\left(\mathrm{ZrSiO}_{4}\right)$ & 50.83 & 64.17 \\
\hline Total dry feed mass ${ }^{\mathrm{b}}(\mathrm{g})$ & 1560.4 & 1711.9 \\
\hline Target glass mass (g) & 1145.3 & 1431.4 \\
\hline Calculated mass loss ${ }^{c}$ & $26.6 \%$ & $16.4 \%$ \\
\hline
\end{tabular}

${ }^{\mathrm{a}}$ These values represent the amounts of additives mixed into $1 \mathrm{~L}$ of as-prepared simulated waste (i.e., the feed volume increases after adding the additives).

${ }^{\mathrm{b}}$ Sum of all simulated waste chemicals plus additives excluding estimated water.

${ }^{c}$ A difference between the total dry mass of feed components and target glass mass divided by the total dry mass of feed components.

“.” indicates zero value.

For the simulated waste, each chemical was added to deionized (DI) water in a predetermined order and was allowed to dissolve completely before the next chemical was added to ensure that all components are fully dissolved. A mix of additive chemicals/minerals was added to the simulated waste to prepare the slurry feeds (also referred to as "melter feed" or "glass feed;" equivalent to "glass batch" in commercial glass production). The slurry feed then was thoroughly mixed and dried at $105^{\circ} \mathrm{C}$ for $12 \mathrm{~h}$ to obtain the "dried feed" used in various tests described below.

\subsection{Pellet test}

Dried feed was prepared as cylindrical pellets to monitor the volume change during heating according to the methods developed for the feed melting studies by Hrma and others [29,30]. Pellets were made by uniaxial pressing $1.5 \mathrm{~g}$ of dried feed at $7 \mathrm{MPa}$. Each pellet was $13 \mathrm{~mm}$ in diameter and $\sim 6 \mathrm{~mm}$ high. Pellets placed on an alumina plate were heated at $5 \mathrm{~K} / \mathrm{min}$ and photographed through a window in the furnace at a $10-50^{\circ} \mathrm{C}$ interval depending on the temperature range. The images were evaluated in Photoshop $^{\circledR}$ to obtain the area profiles of samples as a function of temperature. 


\subsection{Heat treatment}

The dried feed was treated thermally in a platinum crucible ( $20 \mathrm{~g}$ a batch) by heating at $5 \mathrm{~K} / \mathrm{min}$ to $600,700,800,900,1000$, and $1100^{\circ} \mathrm{C}$. The samples were cooled in air after being heated to the target temperatures. The mass loss measurement was performed by weighing samples before and after the heat treatment.

\subsection{X-ray diffraction}

The dried feed and thermally treated samples (before leaching) were analyzed by X-ray diffraction (XRD) with a Bruker D8 Advance (Bruker AXS Inc.) instrument equipped with a $\mathrm{Cu} \mathrm{K} \alpha$ target at $40 \mathrm{kV}$ and $40 \mathrm{~mA}$. The samples were ground into a fine powder and doped with a known concentration of calcium fluoride as an internal standard. The instrument had a LynxEye positionsensitive detector with a scan range of $3-75^{\circ} 2 \theta$. Scan parameters used for sample analysis were $5-75^{\circ} 2 \theta$ with a step of $0.015^{\circ} 2 \theta$ and a 2.5 -s dwell at each step. TOPAS (Bruker AXS Inc.) software was used to identify and quantify the crystal phases.

\subsection{Leach test}

After heat treatment, the samples were crushed and sieved through a \#10 (2-mm) stainless steel sieve. A three-step leaching procedure was used. A $5 \mathrm{~g}$ sample of the crushed and sieved particles was first leached by $200 \mathrm{~mL}$ DI water at room temperature for $10 \mathrm{~min}$. Then, $5 \mathrm{~mL}$ of solution was taken for chemical analyses (Solution-RT sample) and $5 \mathrm{~mL}$ DI water was added to retain $200 \mathrm{~mL}$ solution. The solids and $200 \mathrm{~mL}$ of solution contained in a sealed vessel were placed in an oven at $80^{\circ} \mathrm{C}$ for $24 \mathrm{~h}$, and $5 \mathrm{~mL}$ of solution was taken (Solution- $80^{\circ} \mathrm{C}$ sample). The particle sample was filtered from the second leach solution and dried, and then it was rinsed in $200 \mathrm{~mL}$ DI water for $10 \mathrm{~min}$ at room temperature. A 5$\mathrm{mL}$ sample also was taken from the 200-mL third step rinsing solution (Solution-RT2 sample). The remaining solid was filtered out and dried as the solid sample for chemical analyses (Solid sample). The 
solid sample after leaching and drying was weighed to determine the mass loss during the leaching process. The three-step leaching procedure is illustrated in Figure 1.

(a) Regular leach: heat-treated samples were crushed

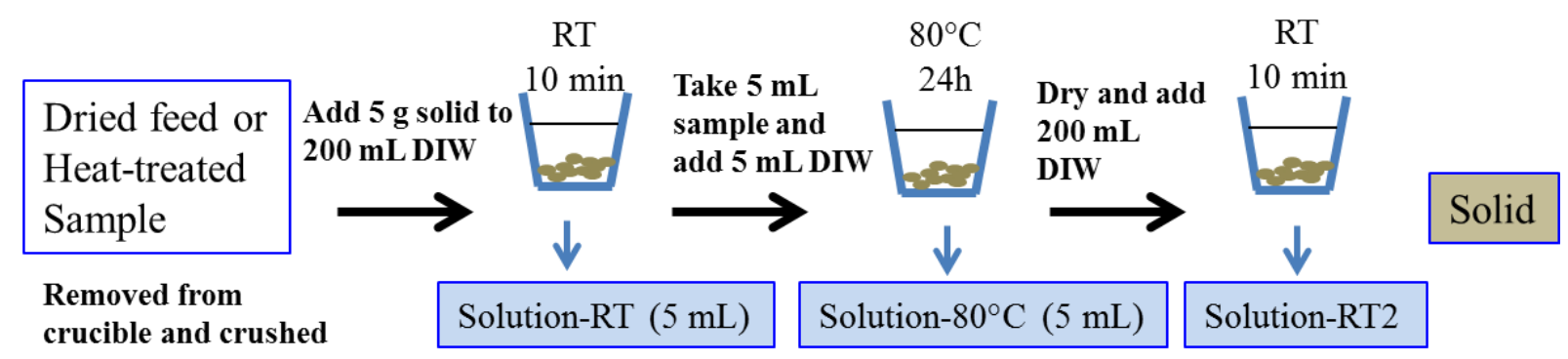

(b) Surface wash: dissolve surface segregated salts in the crucible

\section{Heat-treated Sample $\left(900^{\circ} \mathrm{C}\right.$ and $\left.1000^{\circ} \mathrm{C}\right)$}

As-quenched sample in crucible

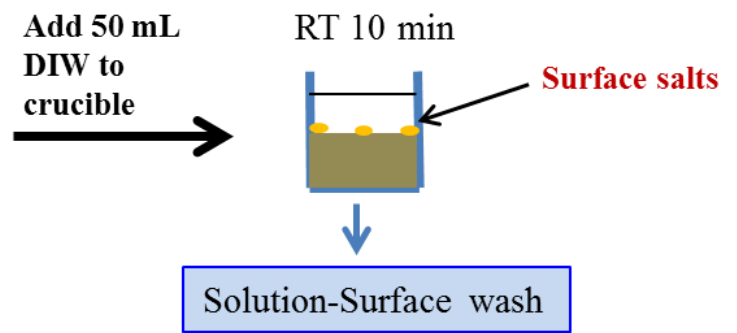

Figure 1. A schematic of leach tests. The surface-wash procedure (b) was only applied to samples heat treated to 900 and $1000^{\circ} \mathrm{C}$ that formed segregated surface salts. The images of the yellow surface salt phase of 900 and $1000^{\circ} \mathrm{C}$ heat-treated samples are shown in Figure 2, which provides the top view of the samples heat treated to different temperatures. 


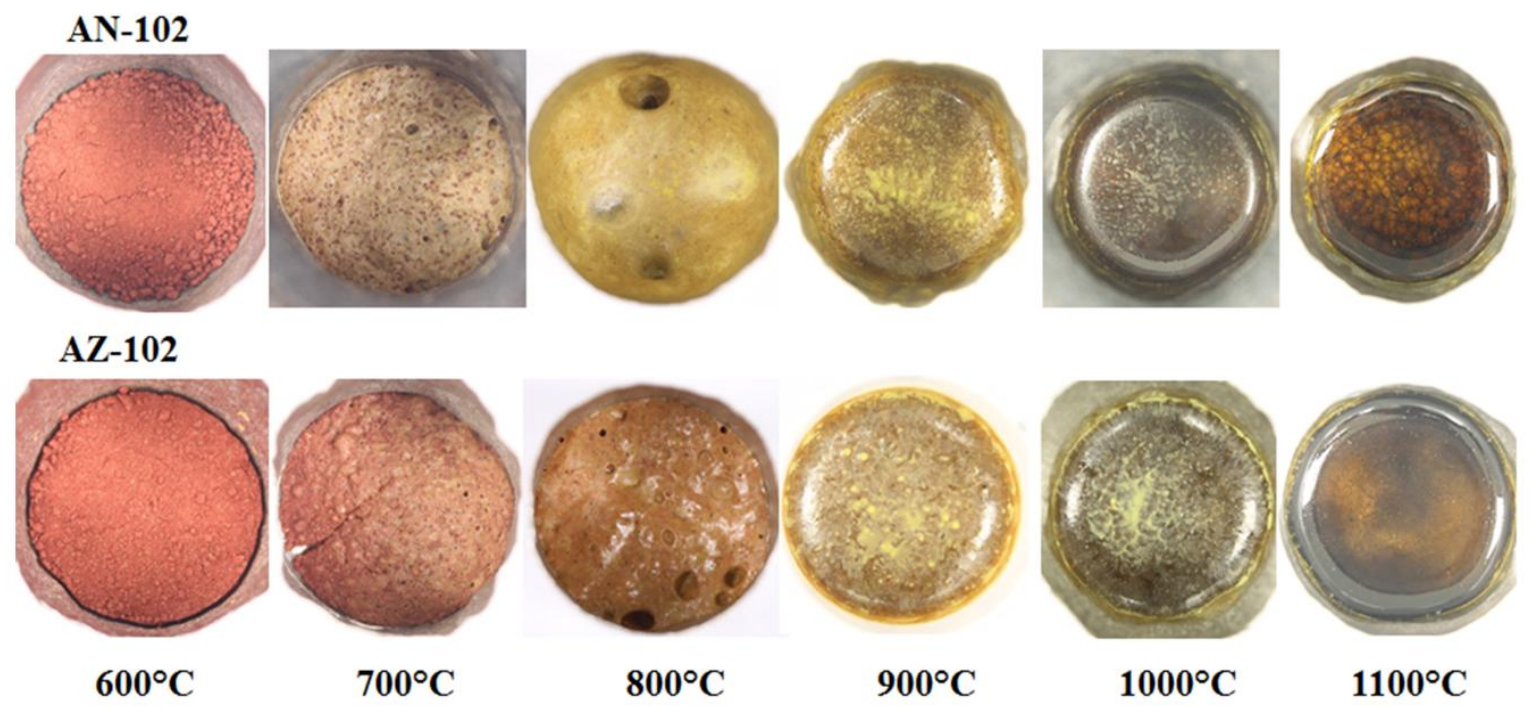

Figure 2. Top view of the samples in crucible after heat treatment to different temperatures.

The first leach at room temperature was intended to dissolve the soluble salt phases while the second leach at $80^{\circ} \mathrm{C}$ was undertaken to solubilize a part of the early glass-forming melts that are nondurable because of low silica content at an early stage of feed melting process. The purpose of the third leach was to determine the amount of soluble phases still adhered to the solids after the second leach solution is drained because of interstitial liquid that cannot be fully drained, which was suggested by Kim et al. 2006 [35]. However, the Solution-RT2 samples from the present study had very small amounts of elements detected by chemical analyses suggesting that the effect of interstitial liquid remained after draining the second leach solution was negligible. Therefore, data from Solution-RT2 samples will not be discussed further.

The samples heat treated at 900 and $1000^{\circ} \mathrm{C}$ had a segregated salt on the melt surface (see Figure 2 for visual images). Therefore, separate heat treatment and leaching were performed to analyze the composition of the segregated salt phase. After heat treating, $20 \mathrm{~g}$ dried feed at $5 \mathrm{~K} / \mathrm{min}$ to 900 and $1000^{\circ} \mathrm{C}$ and cooling in air, the total sample remaining in a platinum crucible was washed with $50 \mathrm{~mL}$ DI water at room temperature for $10 \mathrm{~min}$ [Figure 1(b)]. 


\subsection{Chemical analyses}

Chemical analyses were performed at the Southwest Research Institute (SwRI) ${ }^{1}$ using its standard procedures. The solution samples from three-step leaching [Solution-RT, Solution- $80^{\circ} \mathrm{C}$, and SolutionRT2 samples in Figure 1(a)] and surface wash [Solution-Surface wash sample in Figure 1(b)] were analyzed by inductively coupled plasma-mass spectroscopy (ICP-MS) for Re and inductively coupled plasma-atomic emission spectroscopy (ICP-AES) for all other cationic elements. Ion chromatography (IC) was used to analyze $\mathrm{NO}_{3}{ }^{-}, \mathrm{NO}_{2}{ }^{-}, \mathrm{F}^{-}$, and $\mathrm{Cl}^{-}$and the total inorganic carbon (TIC) method was used for $\mathrm{CO}_{3}{ }^{2-}$. For the remaining dry solids [Solid sample in Figure 1(a)], fusion and acid digestion were performed by SwRI to prepare aqueous solutions first followed by the same ICP-MS, ICP-AEA, IC, and TIC methods for solutions.

\subsection{Mass balance calculation}

Both AN-102 and AZ-102 feed compositions consist of 20 elements total (excluding oxygen), Al, $\mathrm{B}, \mathrm{Ca}, \mathrm{Cr}, \mathrm{Fe}, \mathrm{K}, \mathrm{Li}, \mathrm{Mg}, \mathrm{Na}, \mathrm{Ni}, \mathrm{Pb}, \mathrm{Si}, \mathrm{Ti}, \mathrm{Zn}, \mathrm{Zr}, \mathrm{Cl}, \mathrm{F}, \mathrm{P}, \mathrm{S}$, and Re that remain in glass after melting. There also are $\mathrm{NO}_{3}{ }^{-}, \mathrm{NO}_{2}{ }^{-}, \mathrm{CO}_{3}{ }^{2-}$, organics, and lattice waters that will be lost through evolved gases during melting (Table 1). The ICP-AES, ICP-MS, IC, and TIC methods produce the raw data as element or anion concentrations. The element or anion concentration was converted to the mass of oxides or halogens in the analyzed sample to substantiate the mass balance. For example, components of the mixed salt containing $\mathrm{NaNO}_{3}, \mathrm{NaNO}_{2}, \mathrm{Na}_{2} \mathrm{CO}_{3}, \mathrm{Li}_{2} \mathrm{CO}_{3}, \mathrm{Na}_{2} \mathrm{SO}_{4}$, etc., can be recovered from the masses of $\mathrm{Na}_{2} \mathrm{O}, \mathrm{Li}_{2} \mathrm{O}, \mathrm{N}_{2} \mathrm{O}_{5}, \mathrm{~N}_{2} \mathrm{O}_{3}, \mathrm{CO}_{2}, \mathrm{SO}_{3}$, etc., resulting in the 23 components tracked in this study: $\mathrm{Al}_{2} \mathrm{O}_{3}$, $\mathrm{B}_{2} \mathrm{O}_{3}, \mathrm{CaO}, \mathrm{Cr}_{2} \mathrm{O}_{3}, \mathrm{Fe}_{2} \mathrm{O}_{3}, \mathrm{~K}_{2} \mathrm{O}, \mathrm{Li}_{2} \mathrm{O}, \mathrm{MgO}, \mathrm{Na}_{2} \mathrm{O}, \mathrm{NiO}, \mathrm{PbO}, \mathrm{SiO}_{2}, \mathrm{TiO}_{2}, \mathrm{ZnO}, \mathrm{ZrO}_{2}, \mathrm{Cl}, \mathrm{F}, \mathrm{P}_{2} \mathrm{O}_{5}, \mathrm{SO}_{3}$, $\mathrm{N}_{2} \mathrm{O}_{5}, \mathrm{~N}_{2} \mathrm{O}_{3}, \mathrm{CO}_{2}$, and $\mathrm{Re}$ (Re is tracked by element).

If we include the gas phase (not analyzed in this study), each dried feed or heat-treated sample can be profiled by the mass of the 23 components in four phases defined below. The total mass of these components is computed as:

\footnotetext{
${ }^{1}$ Southwest Research Institute, 6220 Culebra Rd., San Antonio, Texas 78238-5166 (http://www.swri.org/).
} 


$$
m_{t o t}=\sum_{i=1}^{23} \sum_{j=1}^{4} m_{i j}
$$

where $m_{t o t}$ is the total mass of the 23 components in each heat-treated sample or dried feed and $m_{i j}$ is the mass of the $i^{\text {th }}$ component in the $j^{\text {th }}$ phase in each heat-treated sample or dried feed. The term, $j$, consists of the three phases resulting from chemical analyses of two solutions and one solid plus the gas phase as a balance (i.e., the soluble phase leached at room temperature [abbreviated as $R T$ ], the soluble phase leached at $80^{\circ} \mathrm{C}[80 \mathrm{C}]$, the insoluble solid phase [insol], and gas phase released to atmosphere [ $\left.\mathrm{gas}\right]$ ).

The total mass of the 23 components in the dried feed, $m_{t o t}^{0}$, is obtained from the analytical results of leach solutions and solid sample by:

$$
m_{t o t}^{0}=\sum_{i=1}^{23} m_{i}^{0}
$$

where $m_{i}^{0}$ is the total mass of the $i^{\text {th }}$ component analyzed in the dried feed, i.e.,

$$
m_{i}^{0}=\sum_{j=1}^{3} m_{i j}^{0}=m_{i, R T}^{0}+m_{i, 80 C}^{0}+m_{i, \text { insol }}^{0}
$$

where $m_{i j}^{0} i s$ the mass of the $i^{\text {th }}$ component in the $j^{\text {th }}$ phase of the dried feed. For two reasons, the value of $m_{t o t}^{0}$ is slightly different from the starting mass of dried feed: 1) the likely presence of lattice water that cannot be analyzed and 2) analytical uncertainty. The $m_{i, R T}^{0}$ and $m_{i, \text { insol }}^{0}$ values are directly calculated from the analytical results of Solution-RT and Solid samples, respectively. Then, because the Solution$80^{\circ} \mathrm{C}$ sample includes the component dissolved during room temperature leach, $m_{i, 80 \mathrm{C}}^{0}$ value is obtained by subtracting $m_{i, R T}^{0}$ from the mass of the $i^{\text {th }}$ component in the Solution- $80^{\circ} \mathrm{C}$ sample. The removal of the $5 \mathrm{~mL}$ sample from the leach solution was considered when calculating $m_{i, 80 \mathrm{C}}^{0}$. The $m_{i, 80 \mathrm{C}}^{0}$ value is set to zero if it is negative because of analytical uncertainty. 
For the heat-treated samples at temperature $T\left({ }^{\circ} \mathrm{C}\right)$, values for $m_{i, R T}^{T}, m_{i, \text { insol }}^{T}$, and $m_{i, 80 C}^{T}$ are calculated the same way as for the dried feed. For seven volatile components $\left(\mathrm{Re}, \mathrm{SO}_{3}, \mathrm{Cl}, \mathrm{F}, \mathrm{N}_{2} \mathrm{O}_{5}\right.$, $\mathrm{N}_{2} \mathrm{O}_{3}$, and $\mathrm{CO}_{2}$ ), the mass of evolved gases in each heat-treated sample is calculated using Eq. (4):

$$
m_{i, g a s}^{T}=\frac{m_{i}^{0}}{1-L^{T}}-m_{i, R T}^{T}-m_{i, 80 C}^{T}-m_{i, i n s o l}^{T}
$$

where $m_{i j}^{T}$ is the mass of the $i^{\text {th }}$ component in the $j^{\text {th }}$ phase (i.e., $R T$, $80 C$, insol, or gas) of the sample heat treated to $T\left({ }^{\circ} \mathrm{C}\right)$ and $L^{T}$ is the mass loss after heat treatment, which is defined as $L^{T}=\frac{M^{0}-M^{T}}{M^{0}}$, where $M^{0}$ is the mass of dried feed used for heat treatment and $M^{T}$ is the mass of the sample heat treated to $T$. The value of $m_{i, g a s}^{T}$ also is set to zero if negative. Then, $m_{t o t}^{T}$ is calculated by Eq. (1) as expanded in Eq. (5):

$$
m_{t o t}^{T}=\sum_{i=1}^{23} \sum_{j=1}^{4} m_{i j}^{T}=\sum_{i=1}^{23}\left(m_{i, R T}^{T}+m_{i, 80 C}^{T}+m_{i, \text { insol }}^{T}+m_{i, \text { gas }}^{T}\right)
$$

We define three symbols:

$$
\begin{gathered}
f_{i j}^{T}=\frac{m_{i j}^{T}}{m_{i}^{T}}=\frac{m_{i j}^{T}}{\sum_{j=1}^{4} m_{i j}^{T}} \\
F_{i j}^{T}=\frac{m_{i j}^{T}}{m_{t o t}^{T}}=\frac{m_{i j}^{T}}{\sum_{i=1}^{23} \sum_{j=1}^{4} m_{i j}^{T}} \\
w_{i j}^{T}=\frac{m_{i j}^{T}}{m_{j}^{T}}=\frac{m_{i j}^{T}}{\sum_{i=1}^{23} m_{i j}^{T}}
\end{gathered}
$$

where $f_{i j}^{T}$ is the mass fraction of the $i^{\text {th }}$ component in the $j^{\text {th }}$ phase normalized to the total mass of the $i^{\text {th }}$ component $\left(\sum_{j=1}^{4} f_{i j}^{T}=1\right.$ for each $i^{\text {th }}$ component $), F_{i j}^{T}$ is the mass fraction of the $i^{\text {th }}$ component in the $j^{\text {th }}$ 
phase normalized to the total mass of the dried feed or heat-treated sample $\left(\sum_{i=1}^{23} \sum_{j=1}^{4} F_{i j}^{T}=1\right)$, and $w_{i j}^{T}$ is the mass fraction of the $i^{\text {th }}$ component in the $j^{\text {th }}$ phase normalized to the total mass of the $j^{\text {th }}$ phase (i.e., composition of each phase, $\sum_{i=1}^{23} w_{i j}^{T}=1$ for each $j^{\text {th }}$ phase).

\subsection{Retention calculation}

The retention (also called "retention factor" or "retention ratio") of the $i^{\text {th }}$ component in glass after melting, $R_{i}$, is in general defined as [36]:

$$
R_{i}=\frac{g_{i r}}{g_{i t}}
$$

where $g_{i t}$ is the target mass fraction of the $i^{\text {th }}$ component in glass and $g_{i r}$ is the mass fraction of the $i^{\text {th }}$ component retained in final glass product. Because the dried feeds are analyzed in the present study before heat treatment, the composition from the dried feed sample, instead of target composition, provides more accurate assessment, which can eliminate the errors involved in feed preparation. In this study, $R_{i}$ is calculated by assuming that the $1100^{\circ} \mathrm{C}$ sample is a final glass product:

$$
R_{i}=\frac{m_{i, \text { insol }}^{1100}}{\frac{m_{i}^{0}}{1-L^{1100}}}=\frac{m_{i, \text { insol }}^{1100}}{m_{i}^{1100}}=f_{i, \text { insol }}^{1100}
$$

where $m_{i, \text { insol }}^{1100}$ is the mass of the $i^{\text {th }}$ component in the insoluble phase of the sample heat treated to $1100^{\circ} \mathrm{C}$, $L^{1100}\left(\frac{M^{0}-M^{1100}}{M^{0}}\right)$ is the mass loss after heat treatment to $1100^{\circ} \mathrm{C}, m_{i}^{1100}$ is the total mass of the $i^{\text {th }}$ component in the sample heat treated to $1100^{\circ} \mathrm{C}$, and $f_{i, \text { insol }}^{1100}$ is the mass fraction of the $i^{\text {th }}$ component in the insoluble phase of the sample heat treated to $1100^{\circ} \mathrm{C}$ normalized to the total mass of the $i^{\text {th }}$ component. 


\subsection{Results}

\subsection{Visual observation of heat-treated samples}

Figure 2 shows the top view of the samples heat treated to different temperatures. The samples heated to $600^{\circ} \mathrm{C}$ were very similar to those of dried feeds except for some indication of particle sintering and clustering. The segregated salt layer was observed on the surface of the samples after heat treatment to 900 and $1000^{\circ} \mathbf{C}$, with a larger amount observed visually in the AZ-102 glass that had a higher target $\mathrm{SO}_{3}$ concentration. The samples heated to $1100^{\circ} \mathrm{C}$ resulted in a clear glass without any surface salt. It should be noted that both AN-102 and AZ-102 melter feeds did not form an accumulated salt layer during scaled melter tests [37]. A recent study [38] found that the maximum sulfate concentration in the melter feed that does not cause accumulated salt formation is approximately equivalent to the equilibrium solubility of sulfate in glass. Based on the model by Vienna et al. [38], the predicted sulfate solubility is $1.2 \mathrm{wt} \% \mathrm{SO}_{3}$ for both $\mathrm{AN}-102$ and AZ-102 glasses, which is higher than the target concentrations of 0.65 and $0.86 \mathrm{wt} \% \mathrm{SO}_{3}$ for $\mathrm{AN}-102$ and $\mathrm{AZ}-102$ glasses, respectively. Therefore, the separated salt observed in 900 and $1000^{\circ} \mathrm{C}$ samples in this study is only a transient behavior specific to present crucible melting conditions.

\subsection{Volume and mass changes}

Figure 3 shows the photos taken from pellet tests to evaluate the volume expansion of the dried feeds during melting. The expansion of dried feed was profiled by measuring the cross section area from the pictures. Figure 4 shows the normalized area, $A / A_{0}$, as a function of temperature where $A$ and $A_{0}$ are the sample cross section area at a given temperature and at room temperature, respectively. The AN-102 feed started to expand and reached the peak normalized area at a lower temperature with a higher maximum than AZ-102 did. The maximum normalized area of the $\mathrm{AN}-102$ feed is 3.9 at $725^{\circ} \mathrm{C}$ and that of the AZ-102 feed is 2.3 at $775^{\circ} \mathrm{C}$. Figure 4 overlays plots of the mass loss results after heat treatment of $20 \mathrm{~g}$ of dried feeds. As shown in Figure 4, the major mass loss completed by $800^{\circ} \mathrm{C}$ for $\mathrm{AN}-102$ feed and 
by $600^{\circ} \mathrm{C}$ for $\mathrm{AZ}-102$ feed. The feed expansion starts when the viscous glass-forming melts become connected to trap the gases generated from feed melting reactions [30,39], which occurred at about $650^{\circ} \mathrm{C}$ for both AN-102 and AZ-102 feeds in this study. Figure 4 shows that the AN-102 feed was releasing major reaction gases (mass loss up to $\sim 800^{\circ} \mathrm{C}$ ) when the viscous glass-forming melts became connected, resulting in a very rapid volume increase to the peak at $\sim 725^{\circ} \mathrm{C}$. On the other hand, the AZ-102 feed had already released major reaction gases before $600^{\circ} \mathrm{C}$ and, therefore, the expansion progressed slowly, likely by small amount of gases not readily noticeable from the mass loss measurement (Figure 4) with the peak being reached at $\sim 775^{\circ} \mathrm{C}$. In spite of small amount of gases, it can still create appreciable volume expansion which was observed in a study with a simple soda-lime glass batches [39].

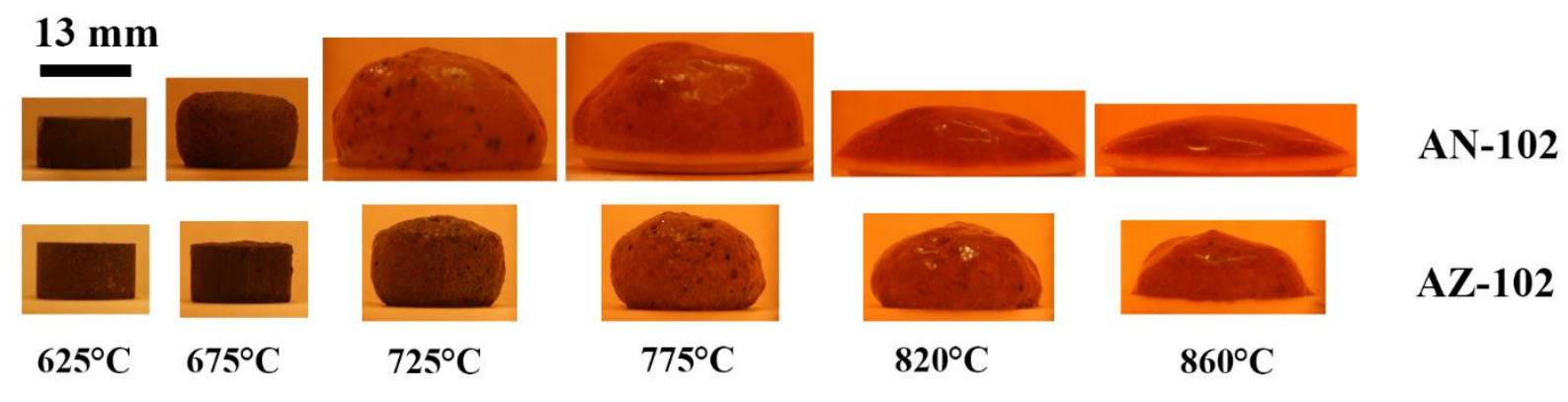

Figure 3. Photographs of pellets of AN-102 and AZ-102 feeds heat treated to different temperatures. 


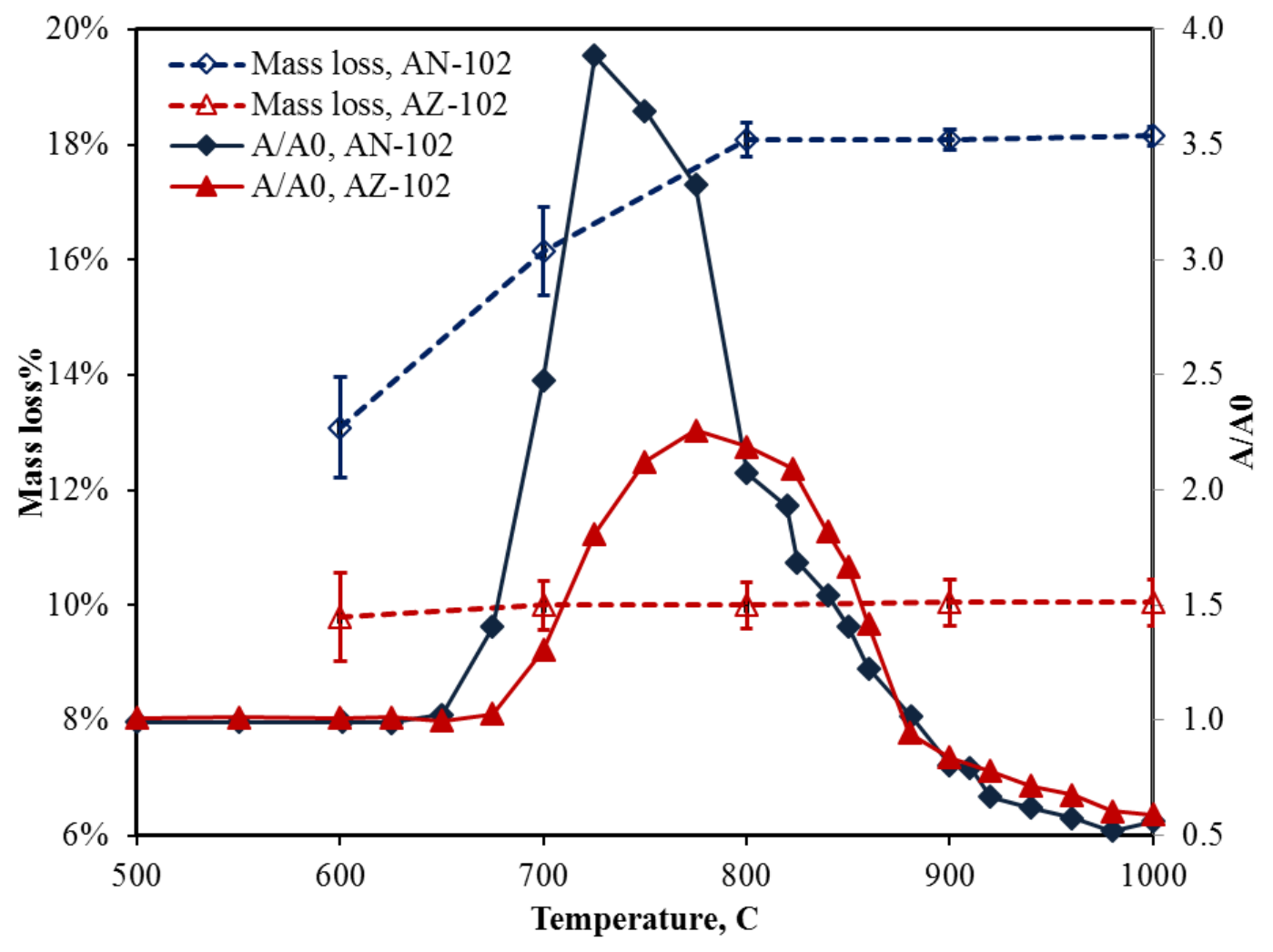

Figure 4. Area ratio to initial area $\left(A / A_{0}\right.$, average value from two tests) and mass loss during the heat treatment $(5 \mathrm{~K} / \mathrm{min})$. The error bars for the mass loss data represent the standard deviations obtained from measurements on four separately-prepared feed samples: for each AN-102 or AZ-102 feed the four samples include one sample in the present study and three samples modified with $\mathrm{SO}_{3}$ concentration only (effect of $\mathrm{SO}_{3}$ concentration on mass loss is negligible) from an ongoing study by the authors to investigate the effect of sulfate concentration on Re behavior.

\subsection{Crystalline phases}

Figure 5 shows the evolution of crystalline phases as a function of final heating temperature starting from the dried feed. The as-determined mass fraction of crystalline phase was normalized to the initial mass of the dried feed based on the measured sample mass loss shown in Figure 4. Table 2 summarizes the measured and calculated crystal contents in the dried feed samples of AN-102 and AZ102 feeds for the waste components with $>2$ mass $\%$ in at least one feed and for all additive components. 
The calculated phase contents are based on the feed compositions given in Table 1. The measured crystal contents are plotted against the calculated contents in Figure 6, which shows a reasonable agreement for the contents identified by XRD analyses considering the difficulties in analyzing the samples with multiple crystalline phases that have many overlapping peaks.

As shown in Figure 5 and Table 2, all of the eight mineral additive components (kyanite through zircon) that are insoluble in water were detected by XRD analyses in the dried feed in both AN-102 and AZ-102 feeds. However, all the waste components, except for $\mathrm{NaNO}_{3}$ in the $\mathrm{AN}-102$ feed, and three water soluble additive components $\left(\mathrm{H}_{3} \mathrm{BO}_{3}, \mathrm{Li}_{2} \mathrm{CO}_{3}\right.$, and $\left.\mathrm{Na}_{2} \mathrm{CO}_{3}\right)$ were not detected in the dried feeds. Some of these components are not expected to be detected by XRD because of low concentrations. However, it is interesting to note that $\mathrm{H}_{3} \mathrm{BO}_{3}, \mathrm{Li}_{2} \mathrm{CO}_{3}$, and $\mathrm{Na}_{2} \mathrm{CO}_{3}$ are present at relatively high concentrations (3.2 to 14.8 mass\%) in the dried feeds but were not detected. The implication of this result will be discussed in connection with the leach test results later in Section 4.2 on the discussion of reactions during slurry preparation and drying. 

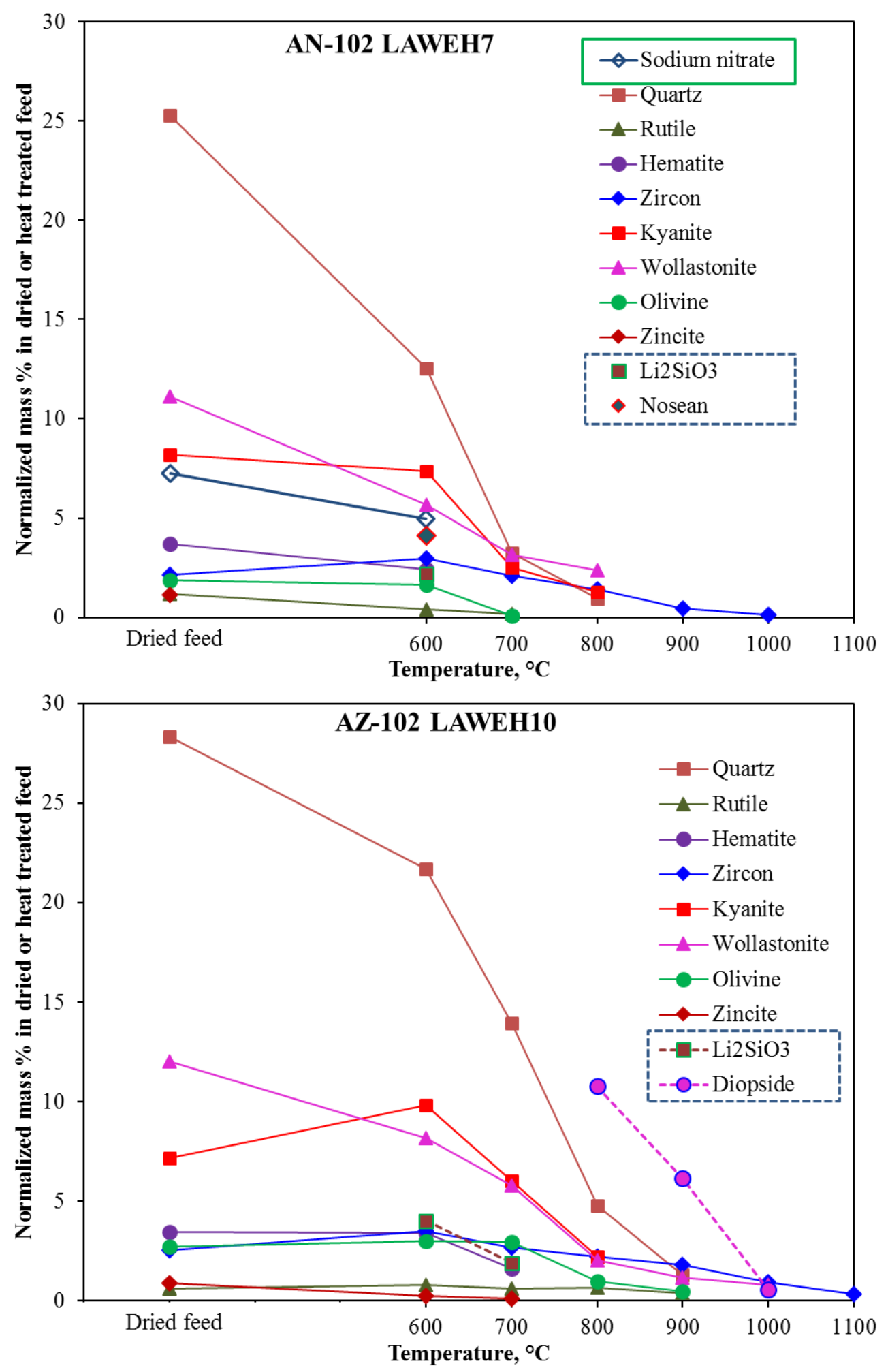

Figure 5. Semi-quantitative XRD crystalline phases in the dried feeds and the heat-treated samples. 
Table 2. Calculated crystal contents in the dried AN-102 and AZ-102 feeds compared with those measured by XRD analyses (in mass\%).

\begin{tabular}{|c|c|c|c|c|}
\hline \multirow[t]{2}{*}{ Component } & \multicolumn{2}{|c|}{ AN-102 } & \multicolumn{2}{|c|}{ AZ-102 } \\
\hline & Calculated & XRD & Calculated & XRD \\
\hline Kyanite $\left(\mathrm{Al}_{2} \mathrm{SiO}_{5}\right)$ & 6.3 & 8.2 & 8.7 & 7.1 \\
\hline Wollanstonite $\left(\mathrm{CaSiO}_{3}\right)$ & 10.0 & 11.1 & 12.6 & 12.0 \\
\hline Hematite $\left(\mathrm{Fe}_{2} \mathrm{O}_{3}\right)$ & 3.8 & 3.7 & 4.2 & 3.5 \\
\hline Olivine $\left(\mathrm{Mg}_{2} \mathrm{SiO}_{4}\right)$ & 2.3 & 1.9 & 5.1 & 2.7 \\
\hline Quartz $\left(\mathrm{SiO}_{2}\right)$ & 23.2 & 25.3 & 27.6 & 28.4 \\
\hline Rutile $\left(\mathrm{TiO}_{2}\right)$ & 1.0 & 1.2 & 1.1 & 0.6 \\
\hline Zincite ( $\mathrm{ZnO})$ & 2.5 & 1.1 & 2.9 & 0.9 \\
\hline Zircon $\left(\mathrm{ZrSiO}_{4}\right)$ & 3.3 & 2.1 & 3.7 & 2.5 \\
\hline $\mathrm{NaNO}_{3}$ & 6.1 & 7.2 & 0.6 & ND \\
\hline $\mathrm{Al}\left(\mathrm{NO}_{3}\right)_{3} \cdot 9 \mathrm{H} 2 \mathrm{O}$ & 5.6 & ND & 0.1 & ND \\
\hline $\mathrm{H}_{3} \mathrm{BO}_{3}$ & 12.9 & ND & 14.8 & ND \\
\hline $\mathrm{Li}_{2} \mathrm{CO}_{3}$ & 5.8 & ND & 8.8 & ND \\
\hline $\mathrm{NaOH}$ & 3.4 & ND & 0.2 & ND \\
\hline $\mathrm{NaNO}_{2}$ & 4.2 & ND & 2.1 & ND \\
\hline $\mathrm{Na}_{2} \mathrm{CO}_{3}$ & 3.2 & ND & 4.4 & ND \\
\hline Total $^{\mathrm{a}}$ & 93.4 & 61.8 & 96.9 & 57.7 \\
\hline
\end{tabular}

ND: not detected.

${ }^{a}$ The balance for calculated value is the sum of waste components with $\leq 2$ mass $\%$. 


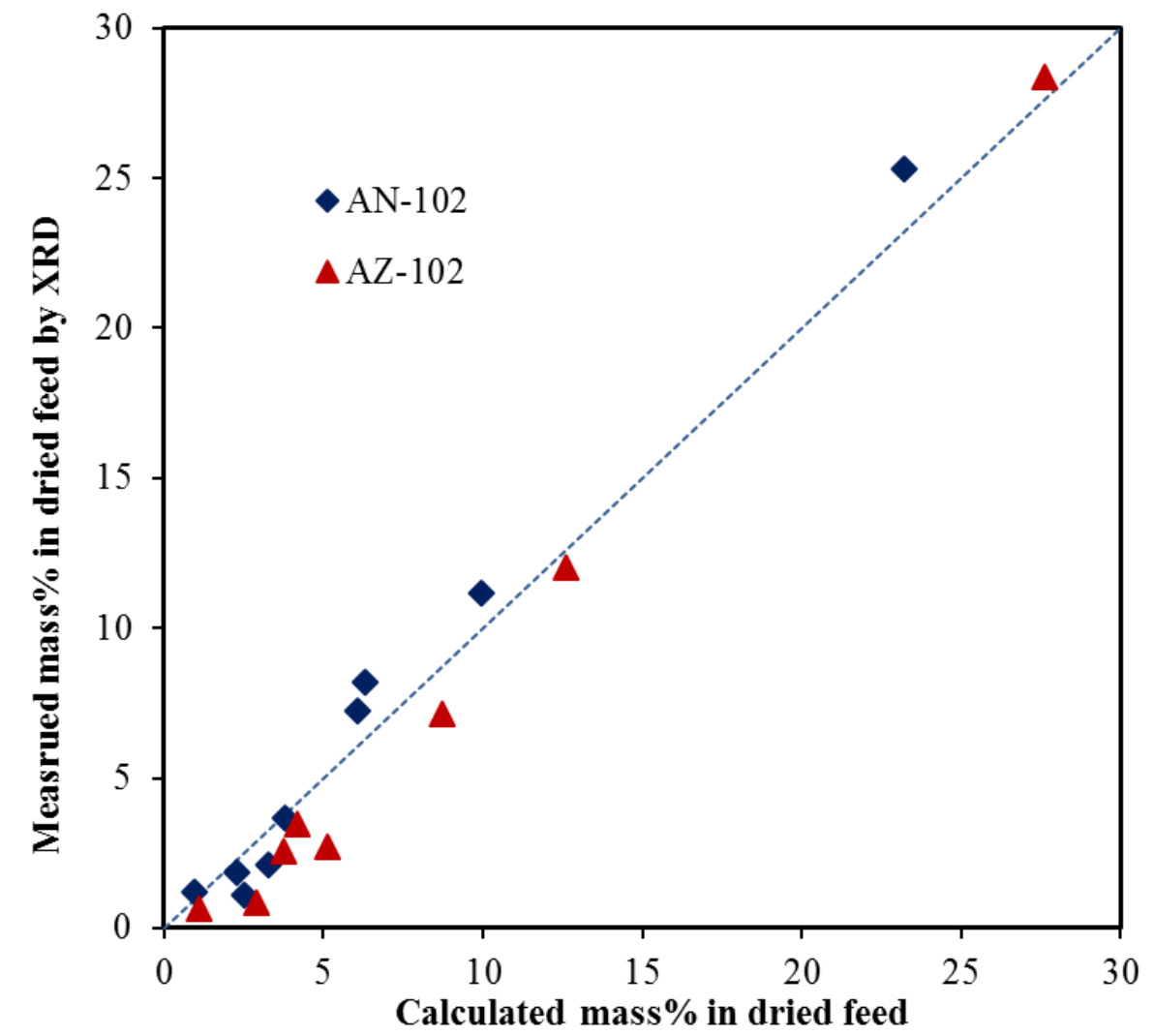

Figure 6. Measured versus calculated mass $\%$ of crystalline phases identified in the dried feed samples (before heat treatment).

As the temperature increases, the feed materials react and convert into the glass-forming melt, and the fraction of crystal phases in the quenched samples gradually decreases. The $\mathrm{NaNO}_{3}$ in the AN102 feed, only waste component detected in the dried feed, remained until $600{ }^{\circ} \mathrm{C}$ and became undetectable by $700^{\circ} \mathrm{C}$. Overall, the mineral additive components dissolved at lower temperatures for the AN-102 feed than that for the AZ-102 feed. For example, quartz remained detectable up to 800 and $900^{\circ} \mathrm{C}$ for $\mathrm{AN}-102$ and $\mathrm{AZ}-102$ feeds, respectively (i.e., all or almost all the quartz dissolved by 900 and $1000^{\circ} \mathrm{C}$ ). Zircon was the last component to dissolve and remained detectable by $1000^{\circ} \mathrm{C}$ for the AN-102 feed and by $1100^{\circ} \mathrm{C}$ for the AZ-102 feed. The faster dissolution of mineral phases in the AN-102 feed is likely attributed to higher total alkali contents in the AN-102 feed, which is consistent with the lower viscosity of AN-102 glass (Figure 7) that resulted in more spread of reacting pellets (see pictures for 
$\geq 820^{\circ} \mathrm{C}$ in Figure 3). Three crystalline phases formed as intermediate reaction products, lithium metasilicate $\left(\mathrm{Li}_{2} \mathrm{SiO}_{3}\right)$, nosean $\left[\mathrm{Na}_{8} \mathrm{Al}_{6} \mathrm{Si}_{6} \mathrm{O}_{24}\left(\mathrm{SO}_{4}\right)\right]$, and diopside $\left(\mathrm{CaMgSi}_{2} \mathrm{O}_{6}\right)$. Lithium metasilicate and nosean were found in the $600^{\circ} \mathrm{C}$ sample only for the $\mathrm{AN}-102$ feed. For the $\mathrm{AZ}-102$ feed, lithium metasilicate was found in 600 and $700^{\circ} \mathrm{C}$ samples, while diopside was present in 800,900 , and $1000^{\circ} \mathrm{C}$ samples.

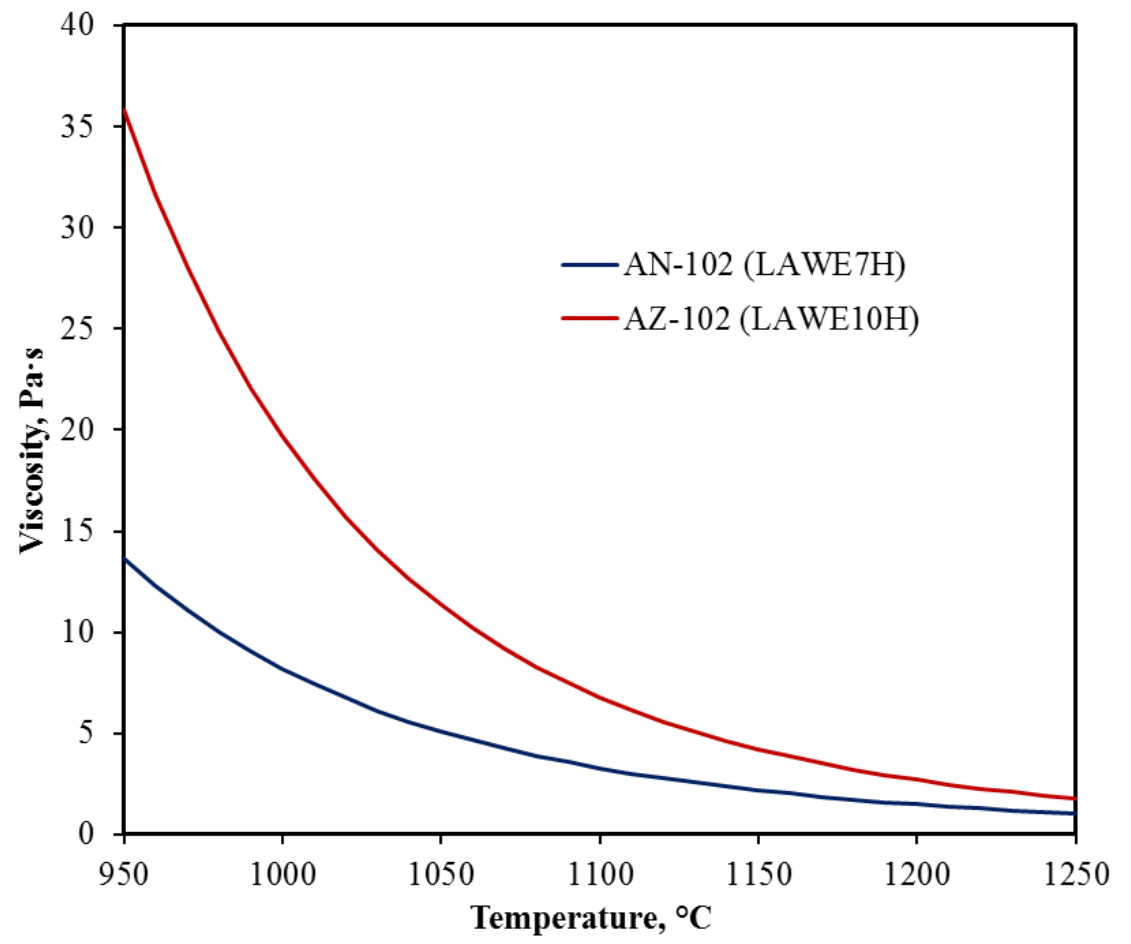

Figure 7. Viscosity of AN-102 and AZ-102 glasses as a function of temperature (data from [37]).

\subsection{Chemical compositions}

Chemical analyses performed by SwRI mentioned in Section 2.6 included replicate analyses for selected components in selected samples. All replicate pairs were compiled to obtain rough estimates of the errors involved in chemical analyses. The relative standard deviation (RSD, standard deviation divided by the mean) was calculated from each replicate pair. For components with multiple replicates, a pooled RSD was calculated using: 


$$
R S D_{i, p}^{2}=\frac{\sum_{k=1}^{N_{i}}\left(n_{i, k}-1\right) R S D_{i, k}^{2}}{\sum_{k=1}^{N_{i}}\left(n_{i, k}-1\right)}
$$

where $R S D_{i, k}$ is the RSD of the $k^{\text {th }}$ replicate pair for the $i^{\text {th }}$ component, $n_{i, k}$ is the number of replicates in the $k^{\text {th }}$ replicate pair for the $i^{\text {th }}$ component, $N_{i}$ is the number of replicate pairs for the $i^{\text {th }}$ component, and $R S D_{i, p}$ is the RSD pooled over $N_{i}$ replicate pairs. Because the replicates in this study involved duplicates only, i.e., $n_{i, k}=2$ for all pairs, Eq. (11) reduces to:

$$
R S D_{i, p}=\sqrt{\sum_{k=1}^{N_{i}} R S D_{i, k}^{2}}
$$

Then, the standard deviation of each analytical result was calculated by multiplying the concentration by RSD and was added to various concentration values in tables and figures where applicable. For gas phase or total concentration, which are calculated from the concentrations in the phases analyzed, an equation for error propagation was applied. As an example for the mass fraction of $i^{\text {th }}$ component in gas:

$$
s_{i, \text { gas }}=\sqrt{s_{i, R T}^{2}+s_{i, 80 C}^{2}+s_{i, \text { insol }}^{2}}
$$

where $s_{i, g a s}, s_{i, R T}, s_{i, 80 C s}$, and $s_{i, i n s o l}$ are the standard deviations for mass fractions of the $i^{\text {th }}$ component in gas, room temperature soluble, $80^{\circ} \mathrm{C}$ soluble, and insoluble phases, respectively.

From chemical analyses of leach solutions and remaining solids, the mass of each component in each phase $\left(m_{i j}\right)$ is obtained. Then, the mass fraction of each component in each phase normalized to the total mass of 23 components $\left(F_{i j}\right)$ is calculated using Eq. (7) for all the dried feeds and heat-treated samples. The $F_{i j}$ values for the dried feeds $\left(F_{i j}^{0}\right)$ are given in Table 3 as one set of examples. For each of the 23 components, the mass fraction in each phase normalized to the initial total mass $\left(f_{i j}\right)$ is calculated using Eq. (6) for all the dried feeds and heat-treated samples. Table 4 shows the $f_{R e, j}$ values for $\operatorname{Re}$ as an example. All the $F_{i j}, f_{i j}$, and $w_{i j}$ values were calculated and evaluated in various plots. The plots of interest will be presented and discussed in Section 4.0 in connection with the results from other tests. 
Table 3. Mass fraction of each $\left(i^{\text {th }}\right)$ component in each $\left(j^{\text {th }}\right)$ phase in the dried feed normalized to the total mass of dried feed ( $F_{i j}$, in mass\% except for Re given in ppm mass). $F_{i, s o l}=F_{i, R T}+F_{i, 80 C}$ and $F_{i}=F_{i, s o l}+F_{i, i n s o l}$

\begin{tabular}{|c|c|c|c|c|c|c|c|}
\hline \multicolumn{8}{|c|}{ AN-102 dried feed } \\
\hline \multirow{2}{*}{ Component } & \multicolumn{5}{|c|}{ Analyzed $^{\mathrm{a}}$} & \multirow{2}{*}{$\frac{\text { Target }^{\mathrm{a}}}{F_{i}}$} & \multirow{2}{*}{$\begin{aligned} & \text { RPD } \\
& (\%)\end{aligned}$} \\
\hline & $F_{i, R T}$ & $F_{i, 80 \mathrm{C}}$ & $F_{i, s o l}$ & $F_{i, \text { insol }}$ & $F_{i}{ }^{\mathrm{b}}$ & & \\
\hline $\mathrm{Al}_{2} \mathrm{O}_{3}$ & 0.060 & 0.012 & 0.072 & 4.51 & $4.58(0.23)$ & 5.10 & -10.2 \\
\hline $\mathrm{B}_{2} \mathrm{O}_{3}$ & 0.80 & 7.45 & 8.25 & - & $8.25(0.29)$ & 8.36 & -1.3 \\
\hline $\mathrm{CaO}$ & - & 0.020 & 0.020 & 5.19 & $5.21(0.64)$ & 5.34 & -2.5 \\
\hline $\mathrm{Cr}_{2} \mathrm{O}_{3}$ & 0.006 & 0.026 & 0.032 & 0.050 & $0.082(0.002)$ & 0.068 & $*$ \\
\hline $\mathrm{Fe}_{2} \mathrm{O}_{3}$ & 0.069 & - & 0.069 & 4.82 & $4.89(0.23)$ & 4.55 & 7.5 \\
\hline $\mathrm{PbO}$ & - & - & - & 0.005 & $0.005(0.0001)$ & 0.008 & $*$ \\
\hline $\mathrm{Li}_{2} \mathrm{O}$ & 0.14 & 2.45 & 2.58 & 0.039 & $2.62(0.04)$ & 2.68 & -2.3 \\
\hline $\mathrm{MgO}$ & - & - & - & 1.37 & $1.37(0.04)$ & 1.26 & 8.3 \\
\hline $\mathrm{NiO}$ & - & - & - & 0.017 & $0.017(0.0003)$ & 0.008 & $*$ \\
\hline $\mathrm{P}_{2} \mathrm{O}_{5}$ & - & 0.011 & 0.011 & 0.062 & $0.073(0.01)$ & 0.10 & $*$ \\
\hline $\mathrm{K}_{2} \mathrm{O}$ & 0.062 & 0.38 & 0.44 & 0.019 & $0.46(0.02)$ & 0.46 & $*$ \\
\hline $\mathrm{SiO}_{2}$ & - & 0.028 & 0.028 & 39.53 & $39.56(4.65)$ & 37.90 & 4.4 \\
\hline $\mathrm{Na}_{2} \mathrm{O}$ & 1.38 & 9.84 & 11.22 & 0.052 & $11.27(0.15)$ & 11.46 & -1.6 \\
\hline $\mathrm{SO}_{3}$ & 0.054 & 0.47 & 0.53 & 0.019 & $0.54(0.03)$ & 0.55 & -1.2 \\
\hline $\mathrm{TiO}_{2}$ & - & - & - & 1.18 & $1.18(0.01)$ & 1.17 & 0.7 \\
\hline $\mathrm{ZnO}$ & 0.071 & - & 0.071 & 2.89 & $2.96(0.04)$ & 2.93 & 1.1 \\
\hline $\mathrm{ZrO}_{2}$ & - & - & - & 2.30 & $2.30(0.10)$ & 2.51 & -8.2 \\
\hline $\mathrm{Cl}$ & 0.034 & 0.16 & 0.19 & - & $0.19(0.01)$ & 0.17 & $*$ \\
\hline $\mathrm{F}$ & 0.031 & 0.004 & 0.035 & - & $0.035(0.003)$ & 0.068 & $*$ \\
\hline $\mathrm{N}_{2} \mathrm{O}_{5}$ & 0.93 & 6.33 & 7.26 & 0.011 & 7.28 & 7.21 & 1.0 \\
\hline $\mathrm{N}_{2} \mathrm{O}_{3}$ & 0.30 & 2.13 & 2.43 & - & 2.43 & 2.64 & -7.9 \\
\hline $\mathrm{CO}_{2}$ & 0.26 & 3.82 & 4.08 & 0.61 & $4.69(0.25)$ & 5.46 & -14.1 \\
\hline $\operatorname{Re}(p p m)$ & 0.99 & 7.11 & 8.09 & - & $8.09(0.26)$ & 6.86 & 18.0 \\
\hline$F_{j}(\mathrm{Sum})$ & 4.20 & 33.14 & 37.33 & 62.67 & 100.00 & 100.00 & NA \\
\hline
\end{tabular}

\begin{tabular}{|c|c|c|c|c|c|c|c|}
\hline \multicolumn{8}{|c|}{ AZ-102 dried feed } \\
\hline \multirow{2}{*}{ Component } & \multicolumn{5}{|c|}{ Analyzed $^{\mathrm{a}}$} & \multirow{2}{*}{$\begin{array}{l}\text { Target }^{\mathrm{a}} \\
F_{i}\end{array}$} & \multirow{2}{*}{$\begin{array}{l}\text { RPD } \\
(\%)\end{array}$} \\
\hline & $F_{i, R T}$ & $F_{i, 80 C}$ & $F_{i, s o l}$ & $F_{i, \text { insol }}$ & $F_{i}{ }^{\mathrm{b}}$ & & \\
\hline $\mathrm{Al}_{2} \mathrm{O}_{3}$ & - & - & - & 4.92 & $4.92(0.25)$ & 5.50 & -10.6 \\
\hline $\mathrm{B}_{2} \mathrm{O}_{3}$ & 4.92 & 4.88 & 9.80 & - & $9.80(0.27)$ & 9.02 & 8.6 \\
\hline $\mathrm{CaO}$ & 0.11 & - & 0.11 & 5.96 & $6.07(0.73)$ & 6.31 & -3.8 \\
\hline $\mathrm{Cr}_{2} \mathrm{O}_{3}$ & 0.043 & 0.029 & 0.072 & 0.030 & $0.10(0.003)$ & 0.073 & $*$ \\
\hline $\mathrm{Fe}_{2} \mathrm{O}_{3}$ & - & - & - & 5.47 & $5.47(0.26)$ & 4.91 & 11.4 \\
\hline $\mathrm{PbO}$ & - & - & - & 0.002 & $0.002(0.00002)$ & 0.009 & $*$ \\
\hline $\mathrm{Li}_{2} \mathrm{O}$ & 0.95 & 3.11 & 4.06 & 0.024 & $4.08(0.05)$ & 3.86 & 5.6 \\
\hline $\mathrm{MgO}$ & - & - & - & 2.75 & $2.75(0.07)$ & 2.67 & 3.0 \\
\hline $\mathrm{NiO}$ & - & - & - & 0.025 & $0.025(0.0005)$ & 0.009 & $*$ \\
\hline $\mathrm{P}_{2} \mathrm{O}_{5}$ & 0.011 & 0.017 & 0.028 & 0.064 & $0.092(0.010)$ & 0.11 & $*$ \\
\hline $\mathrm{K}_{2} \mathrm{O}$ & 0.26 & 0.19 & 0.45 & 0.021 & $0.47(0.01)$ & 0.49 & $*$ \\
\hline
\end{tabular}


- The samples heat treated to low temperatures $\left(\leq 800^{\circ} \mathrm{C}\right)$ are likely very inhomogeneous. Because the samples are ground to coarse particles ( $\# 10, \leq 2 \mathrm{~mm}$ ), a portion of sample taken from the heattreated materials may not always be fully representative. The present particle size was chosen as a compromise because the finer grinding tends to include a large fraction of submicron particles that can cause unwanted leaching of "insoluble" components while particles that are too coarse would have a potential to contain closed pores that cannot be reached by water.

- There likely is some precipitation of the solids from the leach solution, especially the dried feed and the samples heat treated to low temperatures that contain a large amount of soluble phases. Any precipitation of solids will interfere with accurate measurements of soluble concentrations.

- The total mass of each component in each dried feed or heat-treated sample is obtained from analytical results for the three different samples (Solution-RT, Solution- $80^{\circ} \mathrm{C}$, and Solid samples). Both the leach and solution preparation and analysis of each sample add to the combined uncertainty of the total mass of each component and thus the mass balance calculations.

It should also be noted that the temperature in this study refers to the furnace temperature measured near the sample location and may not represent the actual sample temperature because of the difference between thermocouple and sample locations and temperature gradient within the sample from the slow heat transfer of foamy materials (see Figure 3). The temperature difference within the sample changes with temperature because the feed expansion determines sample size and heat transfer coefficient. Considering these various uncertainties, data evaluations and discussions in this study will focus on making engineering judgments based on the overall trend of the results rather than trying to understand all the small differences.

The intention of the $24-\mathrm{h}$ leach at $80^{\circ} \mathrm{C}$ was to gain information about the partitioning of $\mathrm{Re}$ initially present in the soluble salt into partially soluble early glass-forming melt before being incorporated into the final insoluble glass. However, it appears that the 10-min leach at room temperature was not aggressive enough for some samples to fully dissolve the soluble salt, which makes it difficult to 
obtain the originally intended information. Therefore, general data evaluations and discussions in this study will mostly refer to the total "soluble" (abbreviated as sol) phase leached at both room temperature and at $80^{\circ} \mathrm{C}$ (i.e., $m_{i, s o l}=m_{i, R T}+m_{i, 80 C}$ ) when appropriate, although full data are presented in all tables and plots.

Table 3 also includes columns for target $F_{i}$ values and relative percent differences (RPDs) between the target and analyzed $F_{i}$ calculated as RPD $=\left[F_{i}\right.$ (analyzed $)-F_{i}$ (target) $] / F_{i}($ target $) * 100$. The RPD values were provided for the "major" components with $F_{i}(\operatorname{target}) \geq 0.5$ mass $\%$ and also for Re. The largest RPD among the major components was observed for $\mathrm{CO}_{2}$ at $-14.1 \%$ and $-19.8 \%$. The large RPD observed for Re, $18 \%$ and $30.5 \%$, would be the result of difficulties encountered in weighing small quantities of $\mathrm{Re}_{2} \mathrm{O}_{7}$ during feed preparation and analytical bias. The use of the analytical results for the dried feed sample for retention calculation instead of target composition, as discussed earlier, would help to minimize errors from feed preparation (note that only one batch was prepared for each AN-102 or AZ102 feed) and potential bias of the present analytical methods.

Table 5 summarizes the target compositions of simulated wastes, additives, and final glasses in terms of oxides and halogens that remain in glass after melting. Table 5 also includes the measured compositions of the samples heat treated to $1100^{\circ} \mathrm{C}$, which represent the final glass compositions in this study. The measured glass compositions agree well with the target compositions for all major glass components $(\geq 0.5$ mass $\%)$. The volatile components (sulfur and halogens) had measurable loss after melting as was expected.

Table 5. Target compositions of simulated wastes and additives and target and analyzed composition of glass (in mass\% of oxides and halogens).

\begin{tabular}{|c|c|c|c|c|c|c|c|c|}
\hline \multirow[t]{2}{*}{ Comp. } & \multirow[t]{2}{*}{ AN-102 } & \multirow[t]{2}{*}{ Additives } & \multicolumn{2}{|c|}{ AN-102 Glass } & \multirow[t]{2}{*}{ AZ-102 } & \multirow[t]{2}{*}{ Additives } & \multicolumn{2}{|c|}{ AZ-102 Glass } \\
\hline & & & Target & Analyzed $^{\mathrm{b}}$ & & & Target & Analyzed $^{\mathrm{b}}$ \\
\hline $\mathrm{Al}_{2} \mathrm{O}_{3}$ & 6.29 & 5.97 & 6.02 & $5.48(0.28)$ & 0.32 & 6.45 & 6.07 & $5.42(0.28)$ \\
\hline $\mathrm{B}_{2} \mathrm{O}_{3}$ & 0.06 & 11.77 & 9.87 & $9.47(0.36)$ & - & 10.61 & 9.95 & $9.50(0.37)$ \\
\hline $\mathrm{CaO}$ & 0.18 & 7.50 & 6.31 & $6.13(0.75)$ & - & 7.42 & 6.96 & $6.73(0.83)$ \\
\hline
\end{tabular}




\begin{tabular}{|c|c|c|c|c|c|c|c|c|}
\hline $\mathrm{Cr}_{2} \mathrm{O}_{3}$ & 0.49 & - & 0.08 & $0.13(0.01)$ & 1.29 & - & 0.08 & $0.15(0.01)$ \\
\hline $\mathrm{Fe}_{2} \mathrm{O}_{3}$ & - & 6.48 & 5.43 & $5.63(0.26)$ & - & 5.84 & 5.48 & $5.67(0.27)$ \\
\hline $\mathrm{K}_{2} \mathrm{O}$ & 3.33 & - & 0.54 & $0.55(0.02)$ & 8.71 & - & 0.54 & $0.50(0.02)$ \\
\hline $\mathrm{Li}_{2} \mathrm{O}$ & - & 3.78 & 3.17 & $3.14(0.05)$ & - & 4.54 & 4.26 & $4.26(0.07)$ \\
\hline $\mathrm{MgO}$ & - & 1.78 & 1.49 & $1.63(0.04)$ & - & 3.13 & 2.94 & $3.12(0.08)$ \\
\hline $\mathrm{Na}_{2} \mathrm{O}$ & 83.42 & - & 13.53 & $13.48(0.21)$ & 69.84 & 1.48 & 5.72 & $5.81(0.09)$ \\
\hline $\mathrm{NiO}$ & 0.06 & - & 0.01 & $0.02(0.0004)$ & 0.16 & - & 0.01 & $0.03(0.0005)$ \\
\hline $\mathrm{PbO}$ & 0.06 & - & 0.01 & $0.01(0.0001)$ & 0.16 & - & 0.01 & $0.01(0.0001)$ \\
\hline $\mathrm{SiO}_{2}$ & 0.06 & 53.41 & 44.75 & $46.21(5.44)$ & 0.32 & 52.13 & 48.92 & $51.13(6.02)$ \\
\hline $\mathrm{TiO}_{2}$ & - & 1.65 & 1.38 & $1.39(0.01)$ & - & 1.48 & 1.39 & $1.37(0.01)$ \\
\hline $\mathrm{ZnO}$ & - & 4.13 & 3.46 & $3.37(0.05)$ & - & 3.71 & 3.48 & $3.45(0.05)$ \\
\hline $\mathrm{ZrO}_{2}$ & - & 3.53 & 2.96 & $2.74(0.12)$ & - & 3.19 & 2.99 & $2.80(0.12)$ \\
\hline $\mathrm{Cl}$ & 1.23 & - & 0.20 & $0.16(0.01)$ & 3.23 & - & 0.20 & $0.14(0.01)$ \\
\hline $\mathrm{F}$ & 0.49 & - & 0.08 & $0.05(0.004)$ & 1.29 & - & 0.08 & $0.06(0.01)$ \\
\hline $\mathrm{P}_{2} \mathrm{O}_{5}$ & 0.74 & - & 0.12 & $0.15(0.02)$ & 1.94 & - & 0.12 & $0.05(0.01)$ \\
\hline $\mathrm{SO}_{3}{ }^{\mathrm{a}}$ & 3.64 & - & 0.65 & $0.63(0.04)$ & 12.90 & - & 0.86 & $0.76(0.04)$ \\
\hline Sum & 100.00 & 100.00 & 100.06 & 100.37 & 100.00 & 100.00 & 100.06 & 100.95 \\
\hline Loading & 16.22 & 83.78 & & & 6.20 & 93.80 & & \\
\hline $\begin{array}{l}\text { a The ta } \\
\text { The ta } \\
\text { hemati } \\
\text { b Analy? } \\
\text { chemi }\end{array}$ & \multicolumn{8}{|c|}{$\begin{array}{l}\text { The target } \mathrm{SO}_{3} \text { concentrations were } 0.59 \text { mass } \% \text { in } \mathrm{AN}-102 \text { Glass and } 0.80 \text { mass } \% \text { in } \mathrm{AZ}-102 \text { Glass. } \\
\text { The target } \mathrm{SO}_{3} \text { listed in this table was corrected based on the impurity of } 0.45 \text { mass } \% \mathrm{SO}_{3} \text { contained in } \\
\text { hematite }\left(\mathrm{Fe}_{2} \mathrm{O}_{3}\right) \text { raw material. }\end{array}$} \\
\hline
\end{tabular}

As mentioned previously the small amount of segregated salt formed on the surface of the samples heat treated to 900 and $1000^{\circ} \mathrm{C}$ (Figure 2) were washed and analyzed separately from the planned test matrix of heat treatment and leach [Figure 1(b)]. Table 6 summarizes the $F_{i}$ values in the soluble phase from the regular leach $\left(F_{i, s o l}\right)$ and from the surface wash $\left(F_{i, s o l(S W)}\right)$ for the selected components above the reporting limit in at least one sample for both the regular leach and the surface wash. $\mathrm{Na}_{2} \mathrm{O}$ and $\mathrm{SO}_{3}$ were the primary components especially for the surface-wash sample, which is as expected given the salt is primarily $\mathrm{Na}_{2} \mathrm{SO}_{4}$, although some $\mathrm{Na}_{2} \mathrm{O}$ may result from the ion exchange between glass and water. For the surface-wash samples, the presence of a trace amount of $\mathrm{CaO}$ and $\mathrm{SiO}_{2}$ is likely from the very minor dissolution of as-formed glass phase, but it is possible that $\mathrm{Cr}_{2} \mathrm{O}_{3}$ and $\mathrm{Li}_{2} \mathrm{O}$ are parts of the salt; that is, a fraction of $\mathrm{Cr}_{2} \mathrm{O}_{3}$ seems to partition into the salt $\left(\mathrm{as} \mathrm{Cr}^{6+}\right.$, which gives the salt a yellow color) and a small fraction of sulfate could be $\mathrm{Li}_{2} \mathrm{SO}_{4}$. The $F_{i, s o l}$ values for $\mathrm{CaO}$ and $\mathrm{SiO}_{2}$ 


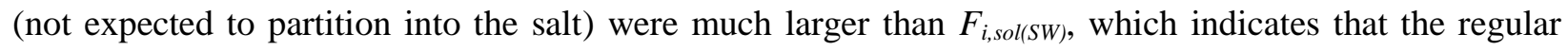
leach (crushing to coarse particles and leaching at $80^{\circ} \mathrm{C}$ for $24 \mathrm{~h}$ ) results in more, although still very minor, dissolution of the "insoluble" phase caused by the large surface area of the crushed samples. Then, a fraction of $\mathrm{Na}_{2} \mathrm{O}$ and $\mathrm{Li}_{2} \mathrm{O}$ in the regular leach may be a result of the dissolution of "insoluble" phase. Therefore, the best component that can be used to determine the amount of salt is $\mathrm{SO}_{3}$. The implication of the results of $F_{S O 3, \text { sol }}$ and $F_{S O 3, \text { sol(SW) }}$ will be discussed later. The soluble Re for the $1000^{\circ} \mathrm{C}$ samples from regular leach was below the reporting limit; however, Re was detected for the surface-wash samples. This is expected the experimental design in that the surface wash used a larger mass of heat-treated sample $(\sim 17 \mathrm{~g}$ versus $5 \mathrm{~g})$ and a smaller volume of DI water $(50 \mathrm{~mL}$ versus $200 \mathrm{~mL})$.

Table 6. $F_{i, s o l}$ (regular leach) and $F_{i, s o l(S W)}\left(\right.$ surface-wash) values for the samples heated to 900 and $1000^{\circ} \mathrm{C}$ (given in mass\% except for Re given in ppm mass).

\begin{tabular}{|c|c|c|c|c|}
\hline \multirow{2}{*}{ Component } & \multicolumn{2}{|c|}{$F_{i, s o l}$, Regular leach } & \multicolumn{2}{|c|}{$F_{i, s o l(S W)}$, Surface wash } \\
\hline & 900 & 1000 & 900 & 1000 \\
\hline \multicolumn{5}{|c|}{ AN-102 } \\
\hline $\mathrm{CaO}$ & $0.013(0.002)$ & $0.010(0.001)$ & $0.0027(0.0003)$ & $0.0020(0.0002)$ \\
\hline $\mathrm{Cr}_{2} \mathrm{O}_{3}$ & $0.0066(0.0003)$ & $0.0018(0.0001)$ & $0.0073(0.0003)$ & $0.0043(0.0002)$ \\
\hline $\mathrm{Li}_{2} \mathrm{O}$ & $0.011(0.002)$ & $0.0079(0.0001)$ & $0.0034(0.0001)$ & $0.0020(0.00003)$ \\
\hline $\mathrm{SiO}_{2}$ & $0.079(0.009)$ & $0.063(0.007)$ & $0.0006(0.0001)$ & 0 \\
\hline $\mathrm{Na}_{2} \mathrm{O}$ & $0.089(0.001)$ & $0.047(0.001)$ & $0.068(0.001)$ & $0.050(0.001)$ \\
\hline $\mathrm{SO}_{3}$ & $0.080(0.005)$ & $0.030(0.002)$ & $0.090(0.005)$ & $0.067(0.004)$ \\
\hline $\mathrm{Re}, \mathrm{ppm}$ & $0.27(0.01)$ & 0 & $0.44(0.02)$ & $0.013(0.001)$ \\
\hline \multicolumn{5}{|c|}{ AZ-102 } \\
\hline $\mathrm{CaO}$ & $0.022(0.003)$ & $0.019(0.002)$ & $0.0088(0.0011)$ & $0.011(0.001)$ \\
\hline $\mathrm{Cr}_{2} \mathrm{O}_{3}$ & $0.0017(0.0001)$ & 0 & $0.0014(0.0001)$ & $0.0008(0.00003)$ \\
\hline $\mathrm{Li}_{2} \mathrm{O}$ & $0.031(0.001)$ & $0.020(0.0003)$ & $0.015(0.0003)$ & $0.014(0.0002)$ \\
\hline $\mathrm{SiO}_{2}$ & $0.079(0.009)$ & $0.071(0.008)$ & $0.0012(0.0001)$ & $0.0005(0.0001)$ \\
\hline $\mathrm{Na}_{2} \mathrm{O}$ & $0.109(0.002)$ & 0 & $0.033(0.001)$ & $0.031(0.0005)$ \\
\hline $\mathrm{SO}_{3}$ & $0.109(0.006)$ & $0.071(0.004)$ & $0.092(0.005)$ & $0.092(0.005)$ \\
\hline $\mathrm{Re}, \mathrm{ppm}$ & $0.35(0.01)$ & 0 & $0.16(0.01)$ & $0.014(0.001)$ \\
\hline
\end{tabular}

Number in parentheses is the standard deviation of chemical analyses. 


\subsection{Discussion}

\subsection{Component groups}

All of the 23 components tracked in this study can be divided into four groups by their partitioning behavior into different phases (soluble, insoluble, gas) during melting as summarized below.

Figure 8 shows the "stacked" plots of $f_{i j}$ over four phases (i.e., $\sum_{j=1}^{4} f_{i j}^{T}=1$ for $i^{\text {th }}$ component) for selected components from each group as a function of temperature. The "Soluble RT" (dark blue) represents the fraction that dissolved at room temperature and the "Soluble 80C" (light blue) represents the fraction that additionally dissolved at $80^{\circ} \mathrm{C}$.

(a) $\mathrm{Na}_{2} \mathrm{O}$
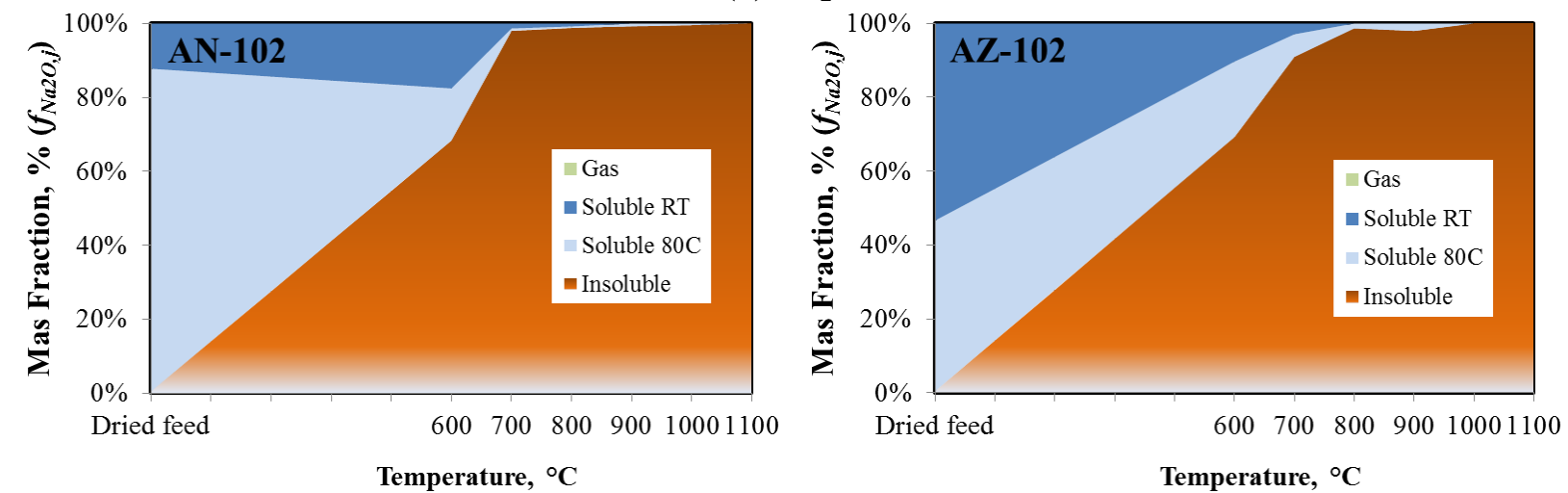

(b) $\mathrm{Cr}_{2} \mathrm{O}_{3}$
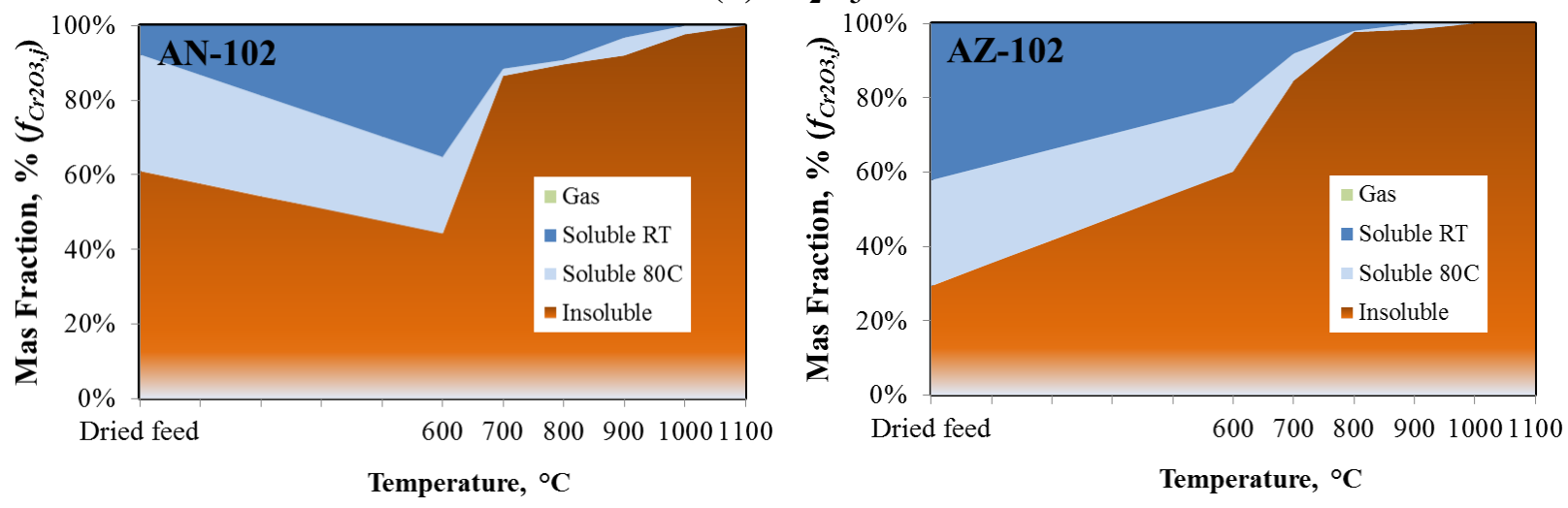

(c) $\mathrm{SO}_{3}$ 

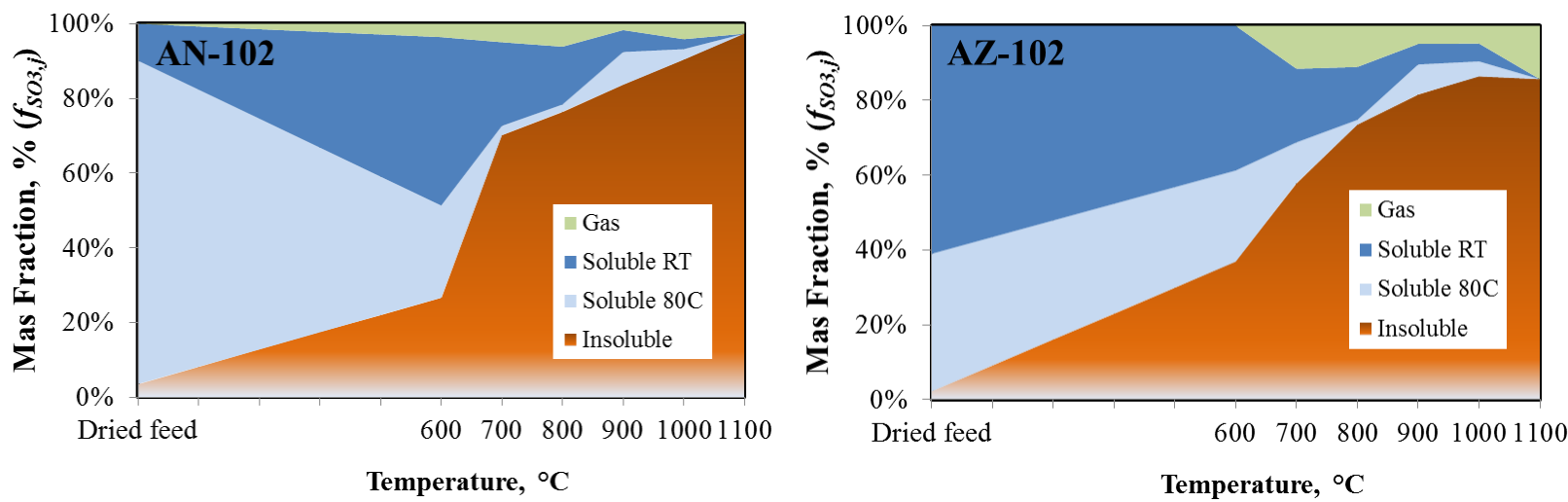

(d) $\mathrm{N}_{2} \mathrm{O}_{5}$
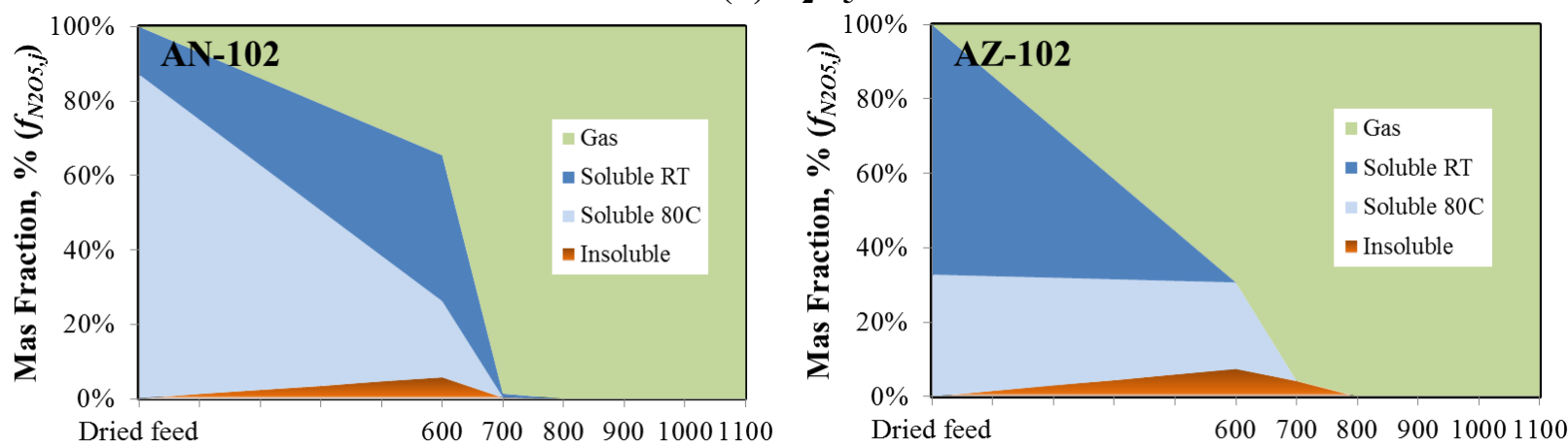

Temperature, ${ }^{\circ} \mathrm{C}$

(e) $\mathrm{CO}_{2}$
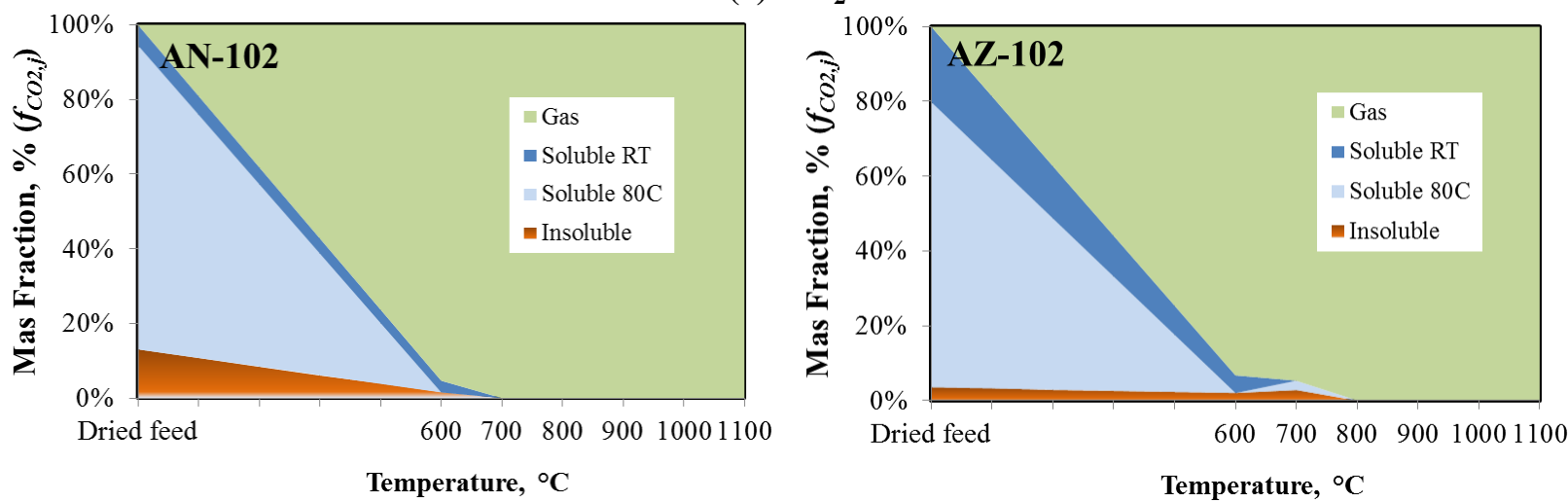

Figure 8. Mass fraction (in mass $\%$ ) of different phases $\left(f_{i j}\right)$ as a function of temperature for selected components.

1. "Insoluble-to-glass:" $\mathrm{SiO}_{2}, \mathrm{Fe}_{2} \mathrm{O}_{3}, \mathrm{Al}_{2} \mathrm{O}_{3}, \mathrm{CaO}, \mathrm{MgO}, \mathrm{TiO}_{2}, \mathrm{ZnO}, \mathrm{PbO}, \mathrm{NiO}$, and $\mathrm{ZrO}_{2}$. These components are initially insoluble and remain insoluble by leaching in all samples from dried feed to heat-treated samples, and they incorporate into glass as temperature increases without any measureable volatile loss. Figure 8 does not include any component from this group because they are $~ 100 \%$ insoluble 
(the lowest was $98.4 \%$ for $\mathrm{Al}_{2} \mathrm{O}_{3}$ ) in all samples from the dried feeds to $1100^{\circ} \mathrm{C}$. Although the $\mathrm{Al}\left(\mathrm{NO}_{3}\right)_{3} \cdot 9 \mathrm{H}_{2} \mathrm{O}$ was soluble when it was added to the simulated $\mathrm{AN}-102$ waste solution (negligible amount in AZ-102 feed, see Table 1), the fraction of soluble $\mathrm{Al}_{2} \mathrm{O}_{3}$ in the dried feed was small $\left(f_{\text {Al2O3,sol }}=\right.$ $1.6 \%$ compared to theoretical value of $16.9 \%$ if all $\mathrm{Al}_{2} \mathrm{O}_{3}$ from $\mathrm{Al}\left(\mathrm{NO}_{3}\right)_{3} \cdot 9 \mathrm{H}_{2} \mathrm{O}$ were soluble). Note that a very small fraction of some component (e.g., $\mathrm{Fe}_{2} \mathrm{O}_{3}$ and $\mathrm{ZnO}$ ) in this group was soluble in the dried feeds, which is likely within experimental error of the present methods. The soluble $\mathrm{CaO}$ from $\mathrm{Ca}\left(\mathrm{NO}_{3}\right)_{2} \cdot 4 \mathrm{H}_{2} \mathrm{O}$ will not be discussed because its concentration in both feeds is too small to be detected accurately by the present methods (see Table 1).

2. "Soluble-to-glass:" $\mathrm{Na}_{2} \mathrm{O}, \mathrm{B}_{2} \mathrm{O}_{3}, \mathrm{Li}_{2} \mathrm{O}, \mathrm{K}_{2} \mathrm{O}, \mathrm{Cr}_{2} \mathrm{O}_{3}$, and $\mathrm{P}_{2} \mathrm{O}_{5}$. These components are initially in soluble forms in dried feed and low-temperature samples but incorporate into glass as temperature increases without any measureable volatile loss. A plot of $f_{N a 2 O, j}$ is shown in Figure 8(a) as a representative component from this group. $\mathrm{Na}_{2} \mathrm{O}, \mathrm{B}_{2} \mathrm{O}_{3}, \mathrm{Li}_{2} \mathrm{O}$, and $\mathrm{K}_{2} \mathrm{O}$ were $\sim 100 \%$ soluble in the dried feeds. However, 30 to $80 \%$ of $\mathrm{Cr}_{2} \mathrm{O}_{3}$, and $\mathrm{P}_{2} \mathrm{O}_{5}$ were insoluble in the dried feeds, as illustrated for $f_{C r 2 O 3, j}$ in Figure 8(b), of which reason is not clear.

3. "Soluble-partially to-glass:" $\mathrm{SO}_{3}, \mathrm{Cl}, \mathrm{F}$, and Re. These components are initially in soluble forms in dried feed and low-temperature samples but partially incorporate into glass and partially volatilize as temperature increases. All four components were $\sim 100 \%$ soluble in the dried feeds. A plot of $f_{S O 3, j}$ is in Figure 8(c) as a representative component from this group. $\mathrm{SO}_{3}, \mathrm{Cl}$, and $\mathrm{F}$ are the important components that contribute to segregated salt layer on glass melt surface $[21,40,41]$ which $\operatorname{Re} / \mathrm{Tc}$ preferentially partitions into and hence has a strong impact on $\mathrm{Re} / \mathrm{Tc}$ retention.

4. "Soluble-to-gas:" $\mathrm{N}_{2} \mathrm{O}_{5}, \mathrm{~N}_{2} \mathrm{O}_{3}$, and $\mathrm{CO}_{2}$. These components are initially in soluble forms in dried feed and low-temperature samples and $100 \%$ volatilizes as temperature increases. A plot of $f_{N 205, j}$ is in Figure 8(d) as a representative component from this group. $\mathrm{N}_{2} \mathrm{O}_{5}$ and $\mathrm{N}_{2} \mathrm{O}_{3}$ were $\sim 100 \%$ soluble in the dried feeds, but 4 to $13 \% \mathrm{CO}_{2}$ was insoluble as shown in Figure 8(e). The implication of these results will be discussed in Section 4.2. A small fraction of $\mathrm{N}_{2} \mathrm{O}_{5}$ was insoluble in the $600^{\circ} \mathrm{C}$ sample for AN-102 
and $600-700^{\circ} \mathrm{C}$ samples for AZ-102 as shown in Figure 8(e), indicating that the heating of dried feeds likely formed a small amount of relatively durable phase that was not leached after $24 \mathrm{~h}$ at $80^{\circ} \mathrm{C}$.

\subsection{Reactions during slurry preparation and drying}

The slurry feed is a complex aqueous solution with many soluble and insoluble components. We will discuss the reactions that have been found to occur during slurry preparation and drying; that is, during mixing of the simulated waste solution with solid additive chemicals and minerals and subsequent drying to obtain the dried feed.

The calculated mass loss given as a difference between the total dry mass of feed components and target glass mass given in Table 1 is $26.6 \%$ and $16.4 \%$ for AN-102 and AZ-102 feeds, respectively, assuming no gas generation or consumption reactions occur during slurry preparation and drying. These theoretical values represent the mass losses if all the dry chemicals listed in Table $\mathbf{1}$ are $100 \%$ converted to the oxides and halogens listed in Table 5. However, the mass loss measured after heating the dried feed to $1100^{\circ} \mathrm{C}$ was $18.2 \%$ and $10.2 \%$ for $\mathrm{AN}-102$ and $\mathrm{AZ}-102$ feeds, respectively (see Figure 4). These smaller measured mass losses after heating to $1100^{\circ} \mathrm{C}$ than the calculated values suggest that there was a net mass loss during slurry preparation and drying, which is calculated as 10.3\% for AN-102 feed and 6.9\% for AZ-102 feed, corresponding to 160 and $119 \mathrm{~g}$ from the total dry feed masses (of the raw chemicals/minerals) given in Table 1. The overall estimated and measured mass changes from dry mix of feed components (i.e., the raw chemicals/minerals) to dried feed and from dried feed to glass is summarized in Figure 9. 


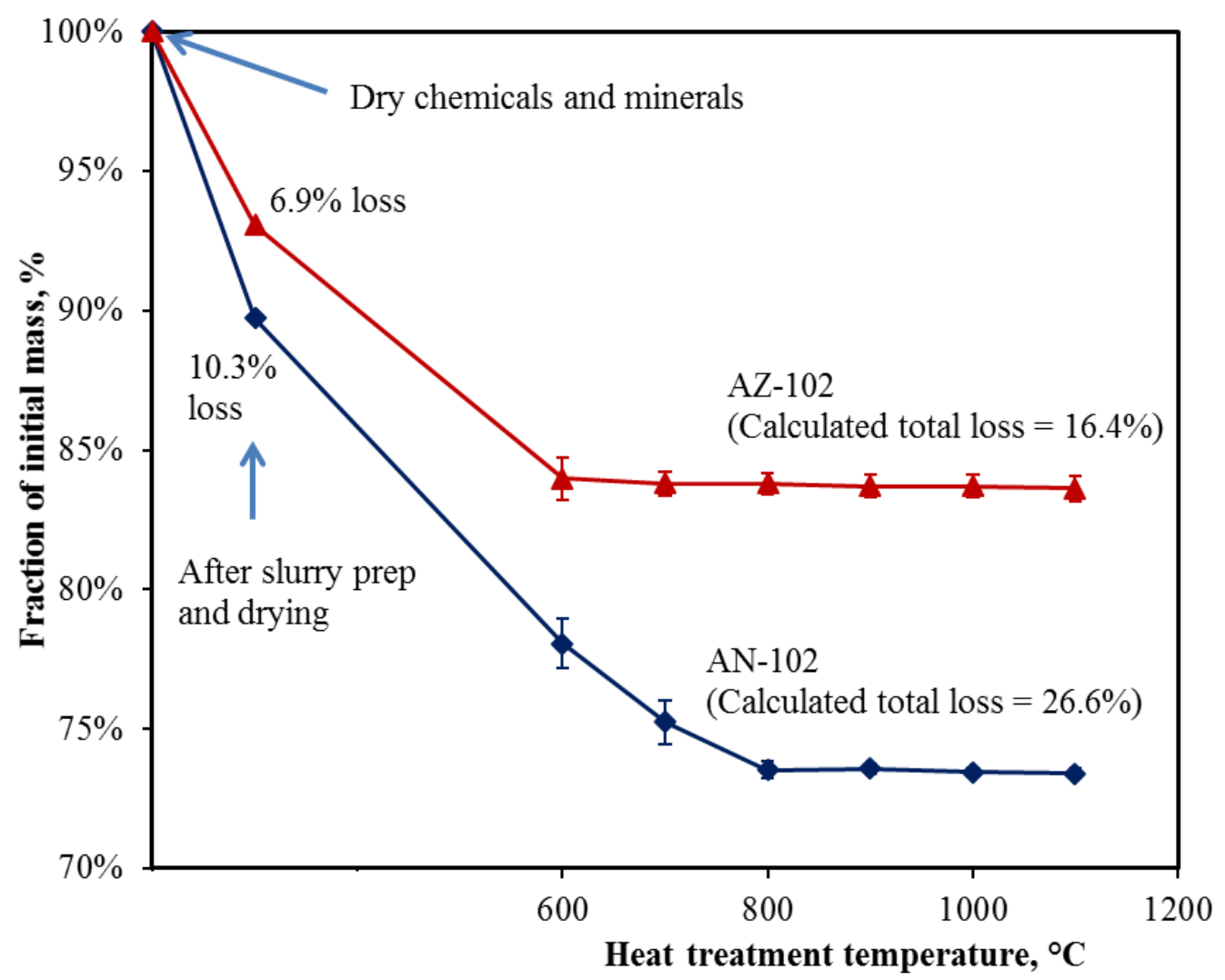

Figure 9. Estimated mass change from dried feed to the final glass. The error bars are the same as given in Figure 4.

Table 7 summarizes the amounts of gaseous components that will be released during conversion from the source chemicals listed in Table 1 to the oxides and halogens given in Table 5. Note that the resulting total mass of gaseous components is the same as the difference between the total dry feed mass and target glass mass given in Table 1. The impurities from the chemicals and minerals were assumed to be released from the feed without remaining in the final glass.

Table 7. Mass of Gaseous Phases in AN-102 and AZ-102 Feeds Given in Table 1 (g per total feed mass)

\begin{tabular}{lcr}
\hline \multicolumn{1}{r}{ Feed } & AN-102 & AZ-102 \\
\hline Hydrated $\mathrm{H}_{2} \mathrm{O}$ & 42.8 & 8.0 \\
$\mathrm{H}_{2} \mathrm{O}$ & 117.3 & 113.2 \\
$\mathrm{~N}_{2} \mathrm{O}_{5}$ & 97.4 & 6.8
\end{tabular}




\begin{tabular}{lcc}
$\mathrm{N}_{2} \mathrm{O}_{3}$ & 35.7 & 19.6 \\
$\mathrm{CO}_{2}$ from carbonates & 73.9 & 121.0 \\
$\mathrm{CO}_{2}$ from organic carbons & 54.0 & 2.2 \\
$\mathrm{O}_{2}{ }^{\mathrm{a}}$ & -26.8 & -1.2 \\
$\mathrm{Impurity}^{\mathrm{b}}$ & 20.8 & 10.9 \\
$\mathrm{~T}$ Total & 415.1 & 280.6 \\
\hline${ }^{\mathrm{a}}$ Net mass gain by oxidation of some chemicals (e.g., $\mathrm{NaCl}$ and $\mathrm{NaHCO}_{2}$ ) \\
${ }^{\mathrm{b}}$ Resulting from chemicals and minerals with purity less than $100 \%$
\end{tabular}

Among the major components with a target concentration $>0.5$ mass $\%$ in Table $\mathbf{3}$, the largest RPD between the target and measured concentrations was observed for $\mathrm{CO}_{2}$ at $-14.1 \%(\mathrm{AN}-102)$ and $-19.8 \%$ (AZ-102) while all others had the RPDs $\pm 11.4 \%$ or less. This suggests a possibility that $\mathrm{CO}_{2}$ (carbonate) was lost during slurry preparation and drying (i.e., there were reactions between feed materials involving carbonates that generated $\mathrm{CO}_{2}$ ). However, when the RPDs for $\mathrm{CO}_{2}$ in Table $\mathbf{3}$ are used, the mass of $\mathrm{CO}_{2}$ lost is $10.4 \mathrm{~g}$ for the AN-102 feed and $24.0 \mathrm{~g}$ for the AZ-102 feed, which are only a small fraction of total estimated mass losses. On the other hand, the RPDs for $\mathrm{N}_{2} \mathrm{O}_{5}$ and $\mathrm{N}_{2} \mathrm{O}_{3}$ were $\pm 7.9 \%$ or less, presumably within experimental error assuming that the RPD of $\pm 11.4 \%$ or less for all major components other than $\mathrm{CO}_{2}$ is a rough estimate of the experimental error (i.e., there was no loss of $\mathrm{NO}_{\mathrm{x}}$ from reactions involving nitrates and nitrites during slurry preparation and drying). Then, it is likely that there was no reaction of the organic carbon components because they are the first to react with nitrates and nitrites. In summary, the estimated mass losses of 160 and $119 \mathrm{~g}$ during slurry preparation and drying can be accounted for primarily by $\mathrm{H}_{2} \mathrm{O}$ from both hydrated water and reaction or decomposition of $\mathrm{H}_{3} \mathrm{BO}_{3}$ and alkali (primarily sodium) hydroxides (but the fraction of $\mathrm{H}_{2} \mathrm{O}$ from hydroxides is relatively small for AN-102 and negligible for AZ-102) in addition to a small amount of $\mathrm{CO}_{2}$. From Table 7, the combined mass of $\mathrm{H}_{2} \mathrm{O}$ from hydrated water and $\mathrm{H}_{3} \mathrm{BO}_{3}$ /hydroxides is 160.1 and $121.2 \mathrm{~g}$ for AN-102 and AZ-102 feeds, respectively, which are very close to the estimated mass losses, suggesting that almost all $\mathrm{H}_{2} \mathrm{O}$ was lost during slurry preparation and drying.

As discussed earlier, $\mathrm{Li}_{2} \mathrm{CO}_{3}, \mathrm{Na}_{2} \mathrm{CO}_{3}$, and $\mathrm{H}_{3} \mathrm{BO}_{3}$ were not detected in the dried feeds by XRD although they were added at relatively high concentrations (3.2 to 14.8 mass\%), which is likely a result of 
these components undergoing the mentioned reactions during slurry preparation and drying producing non-crystalline phases. As mentioned earlier, approximately $90 \%$ of $\mathrm{Al}_{2} \mathrm{O}_{3}$ from soluble $\mathrm{Al}\left(\mathrm{NO}_{3}\right)_{3} \cdot 9 \mathrm{H}_{2} \mathrm{O}$ became insoluble in the dried $\mathrm{AN}-102$ feed although all nitrates including $\mathrm{Al}\left(\mathrm{NO}_{3}\right)_{3} \cdot 9 \mathrm{H}_{2} \mathrm{O}$ were soluble. This implies that other soluble nitrate(s) or compounds were formed from $\mathrm{Al}\left(\mathrm{NO}_{3}\right)_{3}$ during slurry mixing and drying. The soluble nitrate(s) from $\mathrm{Al}\left(\mathrm{NO}_{3}\right)_{3}$ was not likely the sodium nitrate considering that $38.2 \%$ of total $\mathrm{NO}_{3}{ }^{-}$in the $\mathrm{AN}-102$ feed was from $\mathrm{Al}\left(\mathrm{NO}_{3}\right)_{3}\left(61.1 \%\right.$ was from $\mathrm{NaNO}_{3}$ and $0.7 \%$ was from $\left.\mathrm{Ca}\left(\mathrm{NO}_{3}\right)_{2} \cdot 4 \mathrm{H}_{2} \mathrm{O}\right)$ and that the content of sodium nitrate in the AN-102 feed measured by XRD was very close to the target sodium nitrate added.

As was shown in Figure 8(e), the plots of $f_{C O 2, j}$ as a function of temperature, a fraction of carbonate was in an insoluble form in the dried feeds for both AN-102 and AZ-102, which survived up to $700^{\circ} \mathrm{C}$ for AZ-102 feed. This suggests that a portion of the non-crystalline phases that were assumed to be formed during slurry mixing and drying was a carbonate-containing phase that was relatively durable to survive the $80^{\circ} \mathrm{C} 24-\mathrm{h}$ leach. The fact that Re was $100 \%$ soluble in both dried feeds suggests that Re did not partition into this carbonate-containing phase.

\subsection{Feed-to-glass conversion}

During heating of the LAW feed, the crystalline or amorphous phase or their mixture with the lowest melting or eutectic point melts first, forming the initial liquid phase that dissolves other waste components and some additive chemicals. The resulting molten salt, which is water soluble when cooled, decomposes or reacts with the mineral additives producing early glass-forming melts. Initially the reaction gases escape freely from the reacting feeds through low-viscosity molten salt and open pores. As the feed melting reactions progress with temperature, the high-viscosity glass-forming melt forms, becomes connected, and the generated gases are trapped causing the feed to expand as shown in Figure $\mathbf{3}$ and Figure 4. The progress of these feed-to-glass conversion reactions as a function of temperature was monitored by feed expansion, mass loss, XRD analyses, and chemical analyses in this study. Their results are discussed here. 
Figure 10 shows the changes of mass fractions $\left(F_{j}=\sum_{i=1}^{23} F_{i j}\right)$ of the four different phases. For the dried feed before the heat treatment, the AN-102 feed with a higher waste loading had a total of $37.3 \%$ soluble components while AZ-102 had 28.7\%. With increasing temperature, the fraction of soluble components decreases as they become converted into insoluble species and/or gases. Almost all soluble components decreased to $<1 \%$ by $700^{\circ} \mathrm{C}$ for the $\mathrm{AN}-102$ feed and by $800^{\circ} \mathrm{C}$ for the $\mathrm{AZ}-102$ feed. A slightly faster reaction of the soluble phase in $\mathrm{AN}-102$ feed is in line with the phase evolution results observed in the XRD results (see Figure 5) (i.e., faster dissolution of refractory components attributed to higher alkali contents).
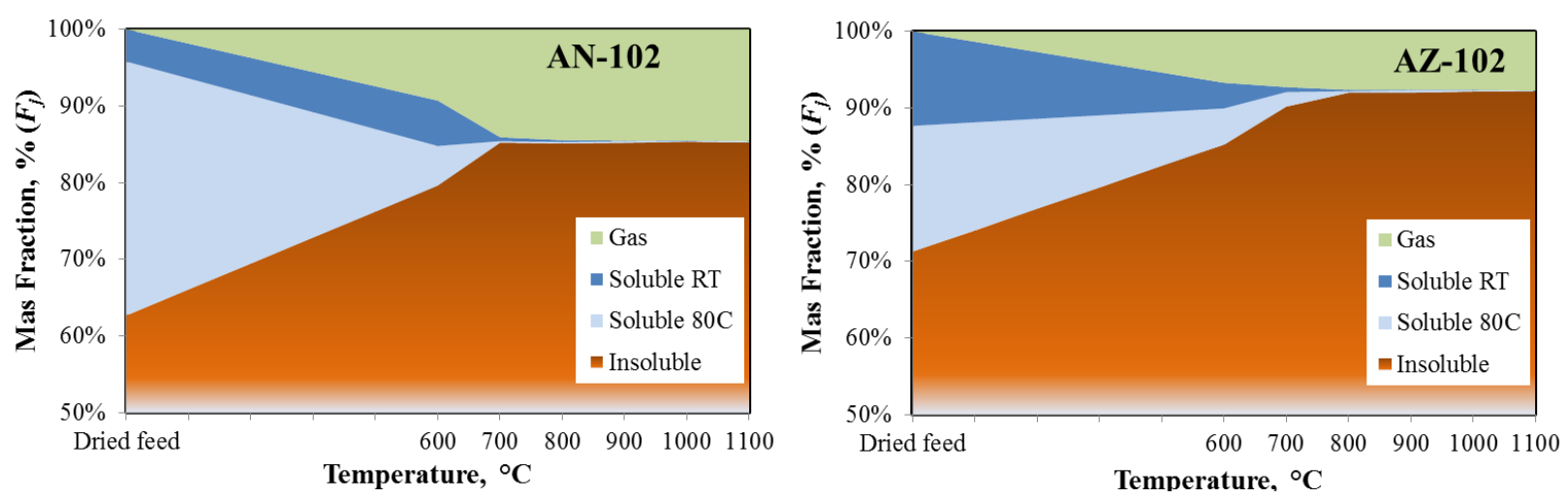

Figure 10. Mass fraction (in mass\%) of different phases $\left(F_{j}\right)$ in the dried feeds and heat-treated samples.

Figure 11 through Figure 13 show the evolution of soluble phases as a function of temperature. The compositions of the soluble phase $\left(F_{i, s o l}\right)$ in AN-102 and AZ-102 are shown in Figure 11 and Figure 12. The seven components $\left(\mathrm{Na}_{2} \mathrm{O}, \mathrm{Li}_{2} \mathrm{O}, \mathrm{B}_{2} \mathrm{O}_{3}, \mathrm{~N}_{2} \mathrm{O}_{5}, \mathrm{~N}_{2} \mathrm{O}_{3}, \mathrm{CO}_{2}\right.$, and $\left.\mathrm{SO}_{3}\right)$ shown in Figure 11 constitute over $96 \%$ of the soluble mass in both the AN-102 and the AZ-102 dried feeds (see Table 3). Figure 12 shows the same plots as in Figure 11 of $\geq 700^{\circ} \mathrm{C}$ for the components still remaining in the soluble phase. Figure 13 compares the mass $\%$ of total soluble components $\left(F_{\text {sol }}\right)$ in each feed. 
(a)

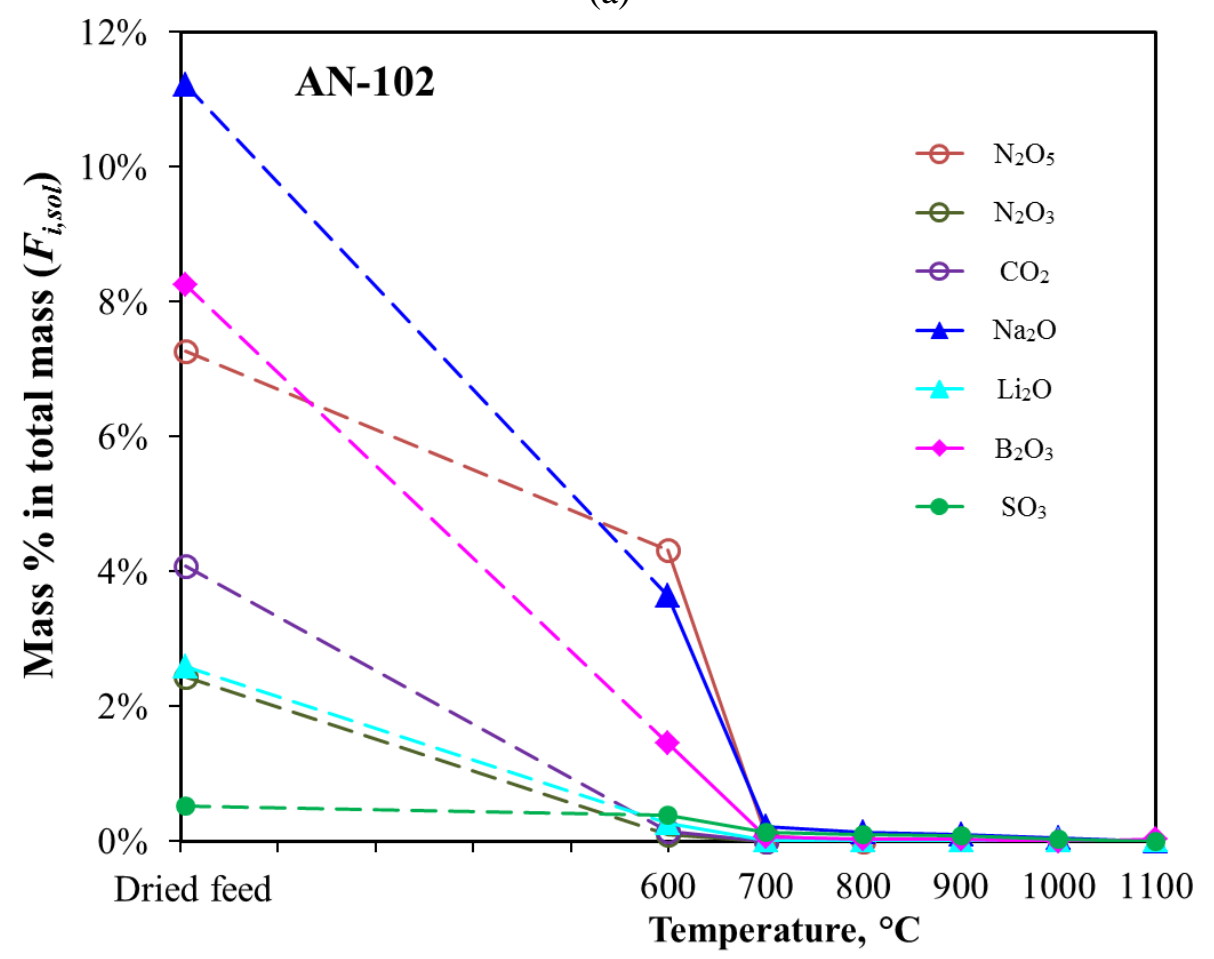

(b)

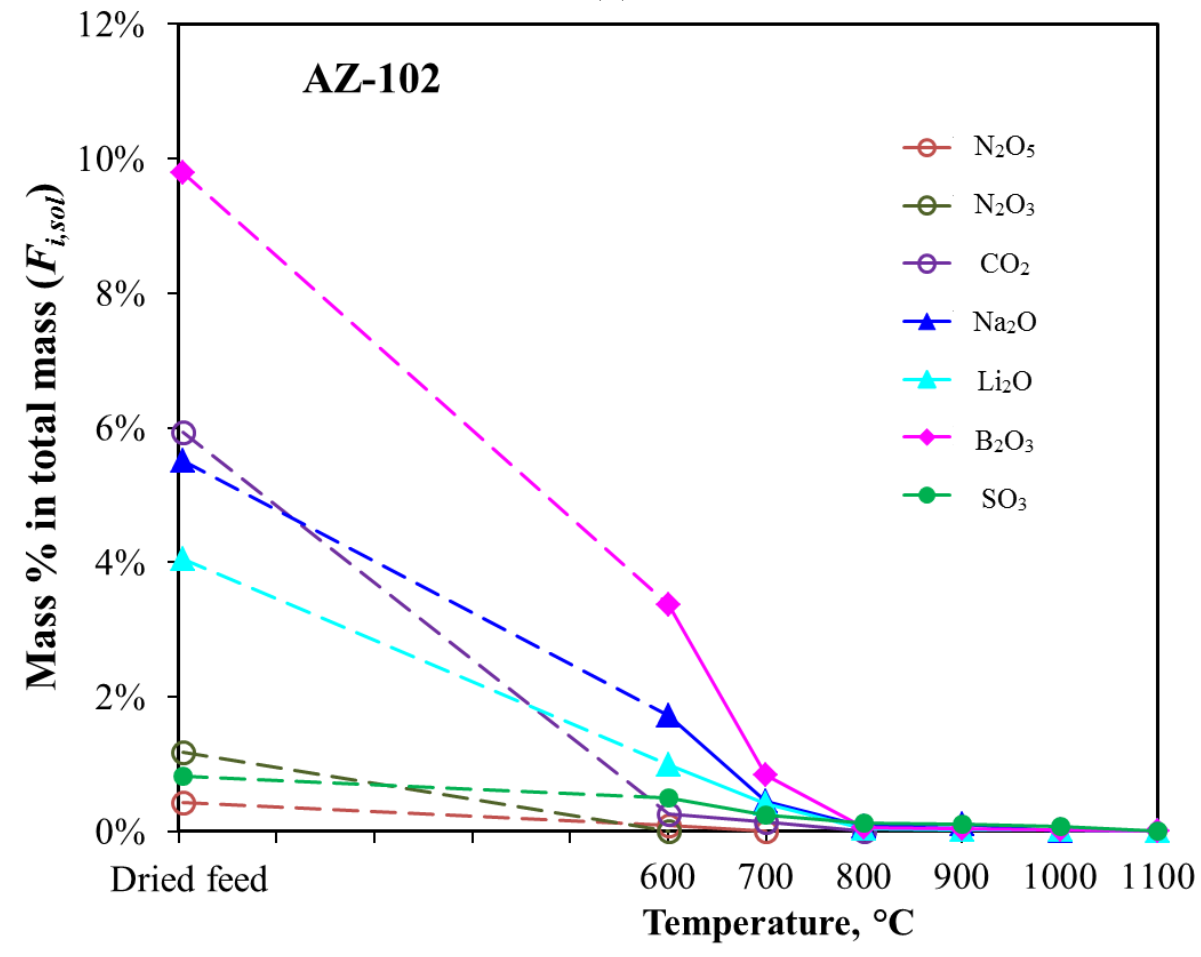

Figure 11. Mass fraction (in mass $\%)$ of soluble component $\left(F_{i, s o l}\right)$ in the dried feeds and heat-treated samples (a) AN-102 feed and (b) AZ-102 feed. 

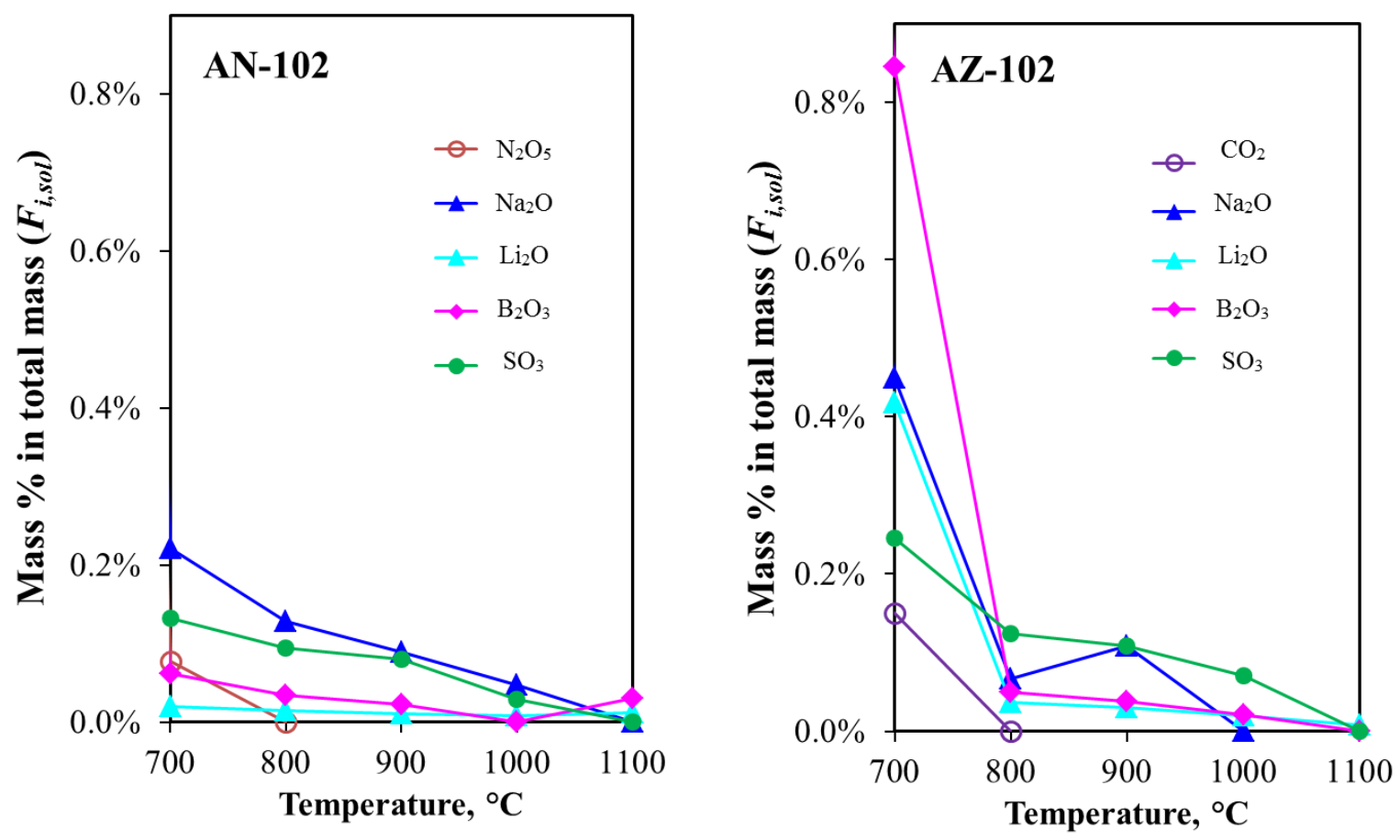

Figure 12. Mass fraction (in mass $\%)$ of soluble component $\left(F_{i, s o l}\right)$ in the heat-treated samples shown for temperatures $\geq 700^{\circ} \mathrm{C}$. 


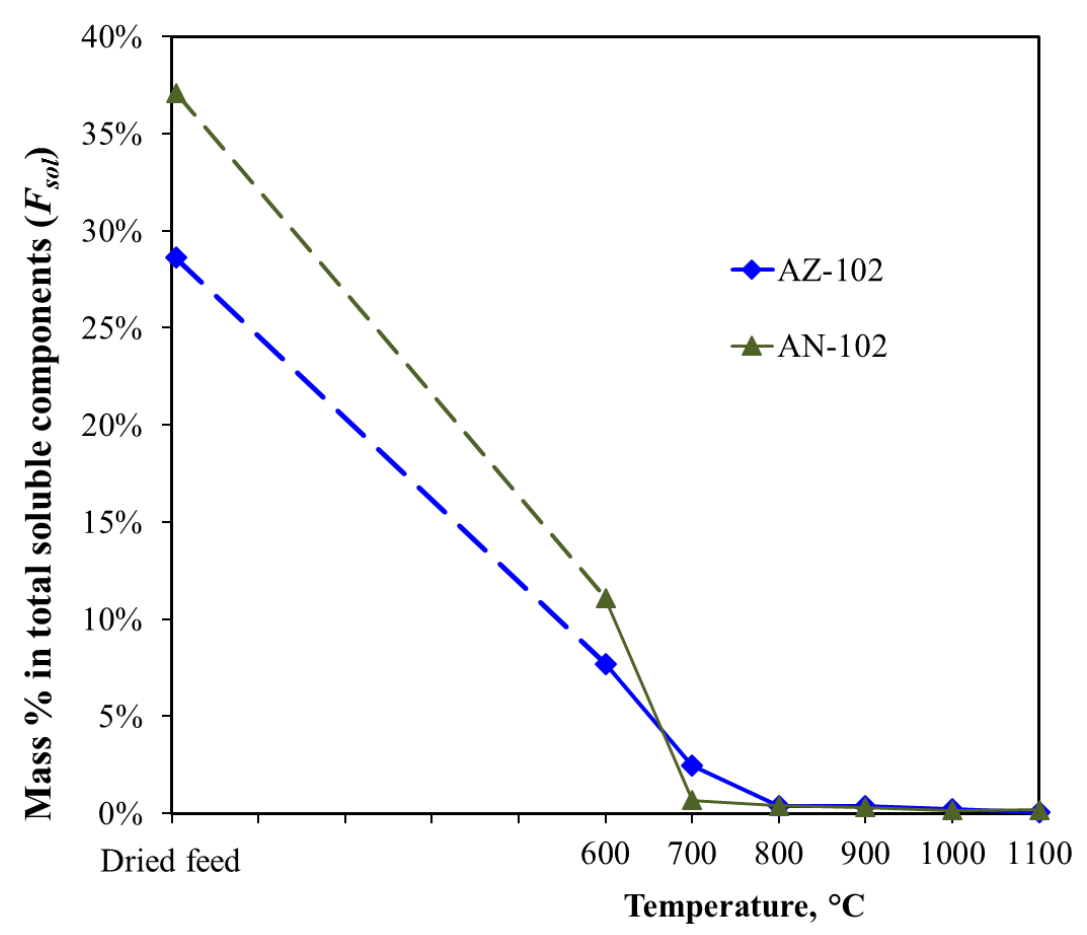

Figure 13. Mass fraction (in mass\%) of total soluble components $\left(F_{s o l}\right)$ in the dried feeds and heat-treated samples.

The anionic components $\left(\mathrm{N}_{2} \mathrm{O}_{5}, \mathrm{~N}_{2} \mathrm{O}_{3}, \mathrm{CO}_{2}\right.$, and $\left.\mathrm{SO}_{3}\right)$ in the soluble salt mix in the dried feeds should have stoichiometric matches with the alkali oxides $\left(\mathrm{Na}_{2} \mathrm{O}\right.$ and $\left.\mathrm{Li}_{2} \mathrm{O}\right)$ (e.g., as in $\mathrm{NaNO}_{3}\left(\mathrm{Na}_{2} \mathrm{O}+\right.$ $\left.\mathrm{N}_{2} \mathrm{O}_{5}=2 \mathrm{NaNO}_{3}\right)$ and $\mathrm{Li}_{2} \mathrm{SO}_{4}\left(\mathrm{Li}_{2} \mathrm{O}+\mathrm{SO}_{3}=\mathrm{Li}_{2} \mathrm{SO}_{4}\right)$, etc). Table 8 summarizes the total moles of alkali oxides and the four anionic components (normalized to per gram of glass) in the dried feeds and the heattreated samples that have the mass percentage of the soluble component $\left(F_{i, s o l}\right)$ more than $1 \%\left(600^{\circ} \mathrm{C}\right.$ sample for $\mathrm{AN}-102$ and $600-700^{\circ} \mathrm{C}$ samples for $\left.\mathrm{AZ}-102\right)$. As shown in Table 8, there are more alkali oxides than the four anionic components for all samples, which suggests that boron is in the form of alkali borates. Table 8 also includes the difference between the moles of total alkali oxides and total anionic components, which represent the "excess" alkali oxides, and the number of moles for $\mathrm{B}_{2} \mathrm{O}_{3}$. The excess alkali oxides were roughly half of the moles of $\mathrm{B}_{2} \mathrm{O}_{3}$ for the dried feeds and were roughly the same as $\mathrm{B}_{2} \mathrm{O}_{3}$ moles for the heat-treated samples. We will assume that the excess alkali oxides and $\mathrm{B}_{2} \mathrm{O}_{3}$ are in the 
form of alkali borates, which are close to $(\mathrm{Na}, \mathrm{Li})_{2} \mathrm{~B}_{4} \mathrm{O}_{7}$ in the dried feeds and $(\mathrm{Na}, \mathrm{Li})_{2} \mathrm{~B}_{2} \mathrm{O}_{4}$ in the heattreated samples.

Table 8. Moles of soluble components (in mmol per g of glass) in the dried feeds and heat-treated samples that have a mass $\%$ of the soluble component $\left(F_{i, s o l}\right)$ more than $1 \%$ (see Figure 11).

\begin{tabular}{lccccccc}
\hline & \multicolumn{2}{c}{$\mathrm{AN}-102$} & & \multicolumn{3}{c}{$\mathrm{AZ}-102$} \\
\cline { 2 - 3 } \cline { 5 - 7 } \multicolumn{1}{c}{ Components } & Dried feed & $600^{\circ} \mathrm{C}$ & & Dried feed & $600^{\circ} \mathrm{C}$ & $700^{\circ} \mathrm{C}$ \\
\hline Total alkali oxides & 2.29 & 0.64 & & 2.15 & 0.61 & 0.21 \\
Total anionic components $^{\mathrm{a}}$ & 1.70 & 0.46 & & 1.57 & 0.13 & 0.06 \\
Difference $^{\mathrm{b}}$ & 0.59 & 0.18 & & 0.58 & 0.47 & 0.15 \\
$\mathrm{~B}_{2} \mathrm{O}_{3}$ & 1.02 & 0.20 & & 1.35 & 0.48 & 0.12 \\
\hline
\end{tabular}

${ }^{\mathrm{a}}$ Expressed in terms of the components tracked in this study, i.e., $\mathrm{SO}_{3}, \mathrm{~N}_{2} \mathrm{O}_{5}, \mathrm{~N}_{2} \mathrm{O}_{3}$, and $\mathrm{CO}_{2}$.

${ }^{\mathrm{b}}$ Difference between the moles of total alkali oxides and total anionic components, which represent the excess total alkali oxides.

The compositions of the soluble phase in the dried AN-102 and AZ-102 feeds are quite different (see Figure 11). The dried AN-102 feed had a roughly comparable mass of $\mathrm{N}_{2} \mathrm{O}_{5}$ and $\mathrm{B}_{2} \mathrm{O}_{3}$ as primary soluble components and had $\mathrm{CO}_{2}$ and $\mathrm{N}_{2} \mathrm{O}_{3}$ as a secondary components (i.e., roughly equal mass of alkali nitrates and borates mixed with lesser alkali carbonates and nitrites). The dried AZ-102 feed had $\mathrm{B}_{2} \mathrm{O}_{3}$ as a primary component and $\mathrm{CO}_{2}$ as a secondary component (i.e., alkali borates are the dominant phase followed by alkali carbonates). Alkali sulfates are the minor salt components in the AN-102 feed, while alkali nitrates and nitrites were present in the AZ-102 feed as minor chemicals in concentrations roughly comparable to alkali sulfates.

After being heat treated to $600^{\circ} \mathrm{C}$, the total mass of soluble components decreased to about onethird of their initial mass for both the AN-102 and AZ-102 feeds (Figure 13). For the $600^{\circ} \mathrm{C}$ samples, sodium nitrate was the dominant form for AN-102 with some alkali borates remaining. For the AZ-102 feed, alkali borates were the only dominant form. All other components, except for $\mathrm{SO}_{3}$, in both feeds decreased to almost zero after heat treating to $600^{\circ} \mathrm{C}$. There was only a slight decrease of $\mathrm{SO}_{3}$ in both dried feeds up to $600^{\circ} \mathrm{C}$ (i.e., sulfate became concentrated in the soluble phase). By $700^{\circ} \mathrm{C}$, virtually all 
the sodium nitrate and alkali borates that remained in the $\mathrm{AN}-102$ feed in the $600^{\circ} \mathrm{C}$ sample disappeared. For the AZ-102 feed, alkali borates and a very small amount of $\mathrm{CO}_{2}$ still remained in the $700^{\circ} \mathrm{C}$ sample, but both of these components disappeared by $800^{\circ} \mathrm{C}$. A small amount of alkali oxides and $\mathrm{B}_{2} \mathrm{O}_{3}$ in the soluble phase is expected to be present from dissolution of very fine particles generated during sample crushing [42]. The presence of these components makes it difficult to use the results of alkali oxides to determine the salt composition for the samples with a very low fraction of soluble phase. As seen from Figure 12, $\mathrm{Na}_{2} \mathrm{SO}_{4}$ was the dominant phase for the samples heat treated to $\geq 700^{\circ} \mathrm{C}$ for the $\mathrm{AN}-102$ feed and $\geq 800^{\circ} \mathrm{C}$ for the AZ-102 feed. Table 9 summarizes the dominant components in the soluble phases of the dried feed and heat-treated samples discussed above.

Table 9. Dominant components in the soluble phases of the dried feed and heat-treated samples (in terms of mass).

\begin{tabular}{ccccc}
\hline Feed & Dried feed & $600^{\circ} \mathrm{C}$ & $700^{\circ} \mathrm{C}$ & $\geq 800^{\circ} \mathrm{C}$ \\
\hline AN-102 & nitrates $\approx$ borates $>$ carbonates & nitrates $>$ borates & sulfates & sulfates \\
AZ-012 & borates $>$ carbonates & borates & borates & sulfates \\
\hline
\end{tabular}

For the AZ-102 feed after heat treatment to $600^{\circ} \mathrm{C}$, almost all of the gas-generating soluble components disappeared (reaction and incorporation of alkali borates remaining in the 600 and $700{ }^{\circ} \mathrm{C}$ samples as dominant components do not evolve gas or cause mass change); therefore, no significant mass loss occurred above $600^{\circ} \mathrm{C}$ as is shown in Figure 4. Only a small amount of $\mathrm{CO}_{2}$ (from carbonate) and $\mathrm{SO}_{2}+\mathrm{O}_{2}$ (from sulfate) gases are generated above $600^{\circ} \mathrm{C}$ as can be inferred from Figure 11 and Figure 12; however, these gases were enough to cause the volume expansion shown in Figure 4 as discussed earlier. For the AN-102 feed, a significant amount of gas-evolving nitrate remained in the $600^{\circ} \mathrm{C}$ sample. The resulting gas was responsible for the major volume increase shown in Figure 4 and mass loss up to $700^{\circ} \mathrm{C}$. However, as can be seen in Figure 12, there is little gas-evolving component remaining at $700^{\circ} \mathrm{C}$ (only a very small amount of nitrate is left), but there still was a significant mass loss between 700 and $800^{\circ} \mathrm{C}$. The reason for this unexplained mass loss is not understood, but it probably is 
caused by material lost around $700^{\circ} \mathrm{C}$ as a result of the vigorous gas evolution when the feed expansion reached the top of the crucible used. No attempts were made to confirm this hypothesis.

By $700^{\circ} \mathrm{C}$ for the $\mathrm{AN}-102$ feed and $800^{\circ} \mathrm{C}$ for the $\mathrm{AZ}-102$ feed, almost all of the soluble

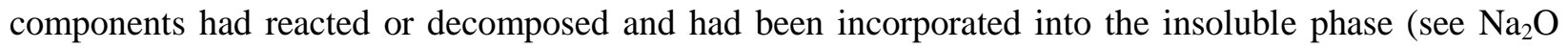
plots in Figure 8(a), $\mathrm{Li}_{2} \mathrm{O}$ and $\mathrm{B}_{2} \mathrm{O}_{3}$ plots were similar); that is, the major feed-to-glass conversion reactions were mostly completed, with a small fraction of refractory additive minerals remaining to dissolve into the pool of inhomogeneous glass-forming melt. Sulfate is the primary salt component still remaining at $\geq 700^{\circ} \mathrm{C}$ for the $\mathrm{AN}-102$ feed and $\geq 800^{\circ} \mathrm{C}$ for the $\mathrm{AZ}-102$ feed. For both feeds, this sulfate formed a surface salt layer on top of the molten glass heat treated to 900 and $1000^{\circ} \mathrm{C}$ as seen in Figure 2 . This salt layer had disappeared on the $1100^{\circ} \mathrm{C}$ samples. It is likely that the sulfate salt was transported to the melt surface by gas bubbles generated from the reactions of the feed-to-glass conversion (refer to Hrma et al. [43] for more detailed discussion).

Figure 14 plots the $F_{S O 3, \text { sol }}$ as a function of temperature for both AN-102 and AZ-102 feeds. Also included in Figure 14 are the plots for the surface-wash test results for the samples heat treated to 900 and $1000^{\circ} \mathrm{C}\left(F_{S O 3, s o l(S W)}\right.$, see Table 6 and corresponding text). The plots for $\geq 800^{\circ} \mathrm{C}$ were inserted into Figure 14 to provide a more detailed comparison between the regular leach and surface-wash results. The mass fraction of sulfate decreased similarly between the two feeds, with the steepest decrease between 600 and $800^{\circ} \mathrm{C}$ (i.e., most rapid incorporation into the glassy phase). After most major reactions were completed and only the sulfate remained, the soluble Re that was not incorporated or volatilized is concentrated in the sulfate. An interesting question here is whether part of the sulfate still remained in the bulk of the melt or if all of the sulfate was on the surface at $900^{\circ} \mathrm{C}$. Figure 14 shows that, at $900^{\circ} \mathrm{C}$, the mass fractions of $\mathrm{SO}_{3}$ from the surface wash, $F_{S O 3, s o l(S W)}$, is comparable to the mass fractions from the regular leach, $F_{S O 3, \text { sol }}$, and likely are within experimental error. For the $1000^{\circ} \mathrm{C}$ samples, the $F_{S O 3, s o l(S W)}$ values are higher than the $F_{S O 3, \text { sol }}$ samples for both the AN-102 and AZ-102 feeds. Overall, these results suggest that all the sulfate salt was transported to the surface; that is, there was little or no unincorporated and segregated sulfate left in the bulk of the melt (in the form of inclusions) at $\geq 900^{\circ} \mathrm{C}$ under the crucible 
melting condition used in this study. The surface-wash results likely are more accurate as long as there was no salt left within the bulk of the melt. The higher $F_{S O 3, s o l(S W)}$ values over the $F_{S O 3, s o l}$, values probably resulted from the potential loss of sulfate layer that was loosely bound to the melt surface during preparation of leach sample (i.e., grinding the glass and collecting $5 \mathrm{~g}$ leach samples from 16 to $18 \mathrm{~g}$ heattreated samples). The surface wash is not subject to these uncertainties.

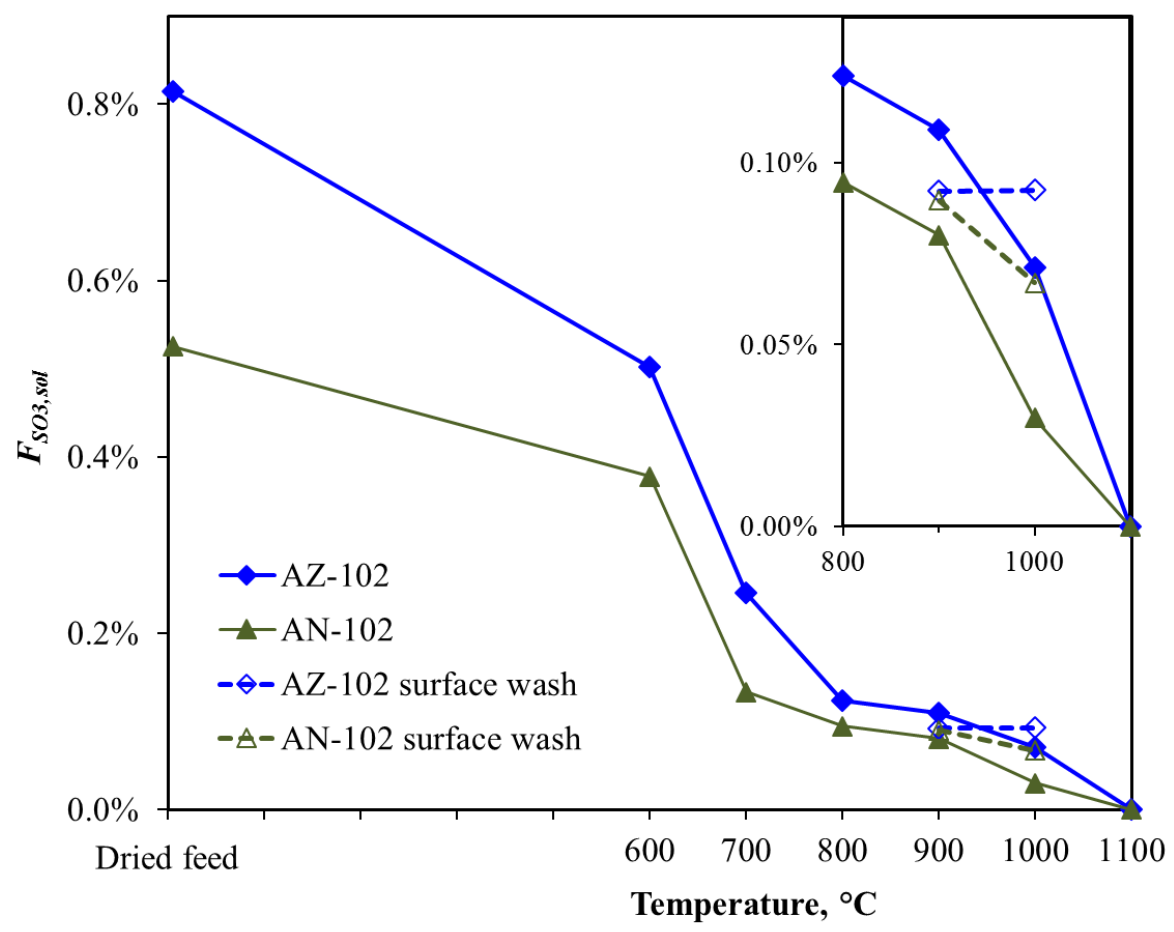

Figure 14. Mass fraction (in mass $\%)$ of $\mathrm{SO}_{3}$ in the soluble phase $\left(F_{S O 3, s o l}\right)$ of the dried feeds and heattreated samples. The open markers represent the data from surface wash.

\subsection{Re partitioning and retention}

Figure 15 shows plots of $f_{R e, j}$ as a function of heat-treatment temperature starting from the feeds. It is clear that incorporation of Re into the insoluble glass-forming melt was almost completed by $700^{\circ} \mathrm{C}$ for both feeds, and the fraction of Re incorporated at $\geq 700^{\circ} \mathrm{C}$ is relatively constant presumably within experimental uncertainty. This observation is very similar to the $F_{j}$ plots in Figure $\mathbf{1 0}$ in that conversion 
of the soluble salt into insoluble glass-forming melt was fully or almost fully completed by $700^{\circ} \mathrm{C}$. The major difference between the $f_{R e, j}$ and $F_{j}$ plots is in the conversion of the soluble phase to gas phase. While the majority of the total soluble phase disappeared by $700^{\circ} \mathrm{C}$ (Figure 10), a large fraction of Re still remains in the very small amount of sulfate salt.
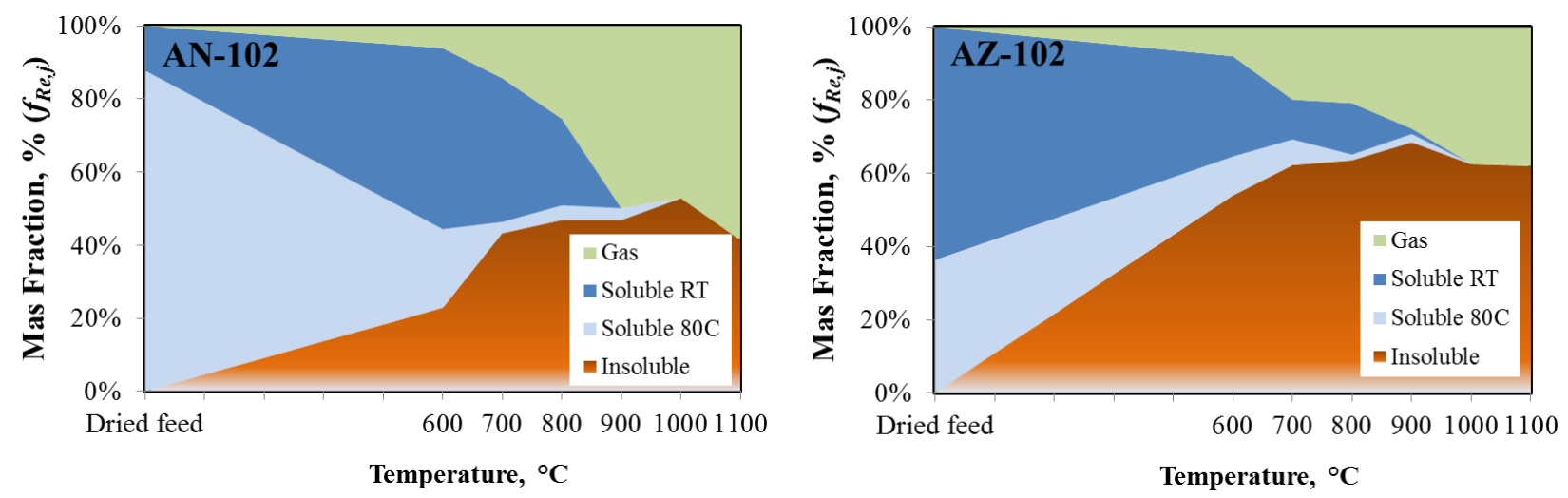

Figure 15. Mass fraction (in mass $\%$ ) of Re in different phases $\left(f_{R e, j}\right)$ of the dried feeds and heat-treated samples as a function of temperature.

The $f_{\text {Re,insol }}$ results in Figure 15 suggest that there was no significant Re loss from the glassforming melt between 700 and $1100^{\circ} \mathrm{C}$ within experimental uncertainty. From crucible tests on $\mathrm{Re}$ volatilization $[21,35]$ and from small-scale melter tests on Re and ${ }^{99 \mathrm{~m}} \mathrm{Tc}$ - volatilization during idling (i.e., no feeding so no cold-cap on the melt surface) [12-14], it was found that Re/Tc volatilizes relatively fast from the glass melt. Matlack et al. [13] fit Re and ${ }^{99 \mathrm{~m}} \mathrm{Tc}$ - volatilization data to a simple equation, $c(t)=$ $c_{0} \exp (-k t)$, where $c$ is concentration, $t$ is time, $c_{0}$ is concentration at $t=0$, and $k$ is rate constant. Using a $k$ value of $0.14 \mathrm{~h}^{-1}$ for ${ }^{99 \mathrm{~m}} \mathrm{Tc}$ at $1100^{\circ} \mathrm{C}\left(k\right.$ value for Re at $1100^{\circ} \mathrm{C}$ was not available) given for one of the LAW glasses (LAWE4H that has the highest $\mathrm{Na}_{2} \mathrm{O}$ concentration among seven representative Hanford LAW glasses), the calculated Re loss is $4.6 \%$ during the 20 -min period between 1000 and $1100^{\circ} \mathrm{C}$ for which the volatilization would be highest. Considering a strong dependence of volatilization from glass on temperature, this rough evaluation suggests that no significant volatilization of Re would be expected between 700 and $1100^{\circ} \mathrm{C}$ from the glass melt. In summary, the Re completes its incorporation into the 
glass melt by approximately $700^{\circ} \mathrm{C}$, and the Re fraction in the glass melt remains reasonably constant up to $1100^{\circ} \mathrm{C}$ under the crucible melting condition used in this study, within the experimental and analytical uncertainties of the methods used.

The mass fractions of Re in soluble phase, $F_{R e, s o l}$ and $w_{R e, s o l}$, as a function of temperature are shown in Figure 16 and Figure 17, respectively. The reasons for the higher initial Re concentration for the AZ-102 feed at the same target Re concentration in the final glass are twofold: 1) the target Re concentration in dried feed is higher for the AZ-102 feed because of the lower ratio of glass to dried feed mass $\left(F_{R e}[\right.$ target $]=7.34 \mathrm{ppm}$ for AZ-102 and $6.86 \mathrm{ppm}$ for AN-102, see Table 3) and 2) the fraction of total soluble phases is lower for the AZ-102 feed $\left(F_{R e}=28.7\right.$ mass \% for AZ-102 and 37.3 mass\% for AN102, see Figure 10). In addition, because of the batching difficulty mentioned earlier (i.e., over-batching of Re for the AZ-102 feed), the RPD between the target and analyzed Re concentration was larger for the AZ-102 feed (see Table 3).

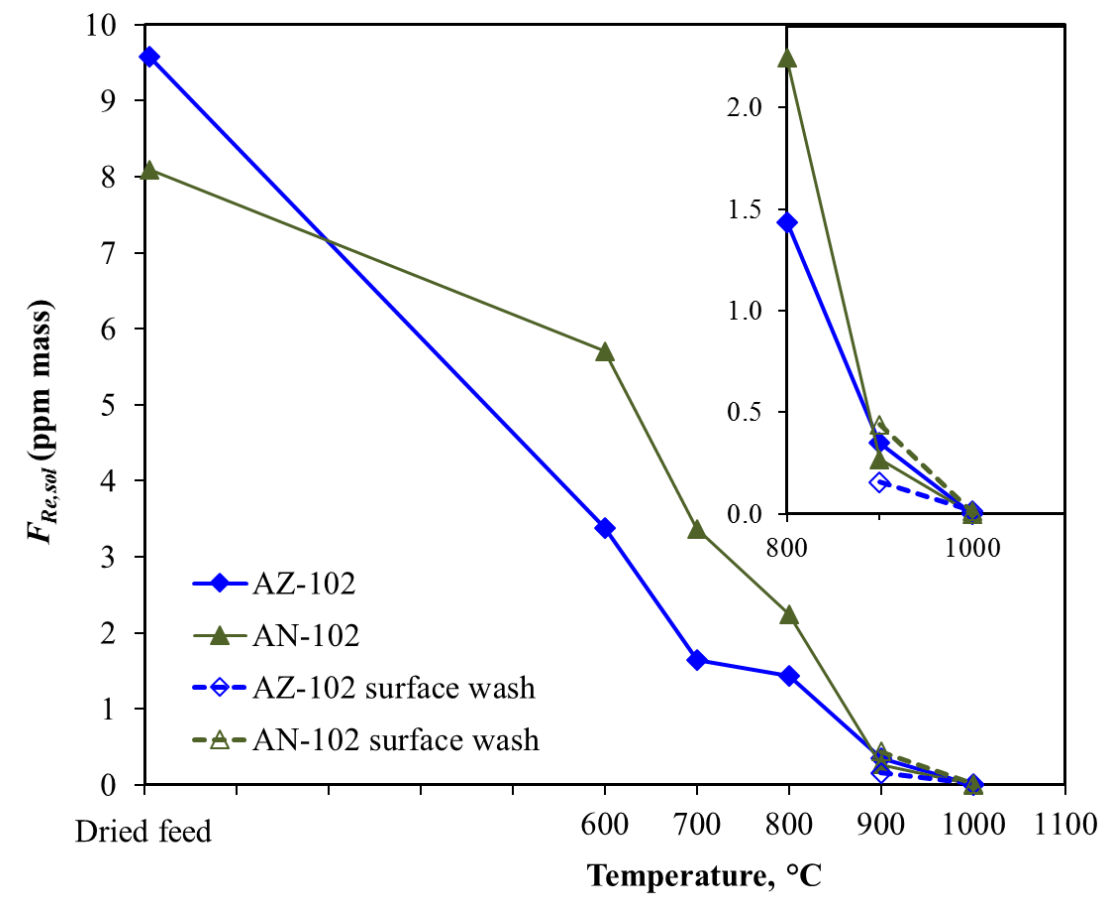

Figure 16. Mass fraction (in ppm mass) of Re in the soluble phase $\left(F_{R e, s o l}\right)$ of the dried feeds and heattreated samples. The dotted lines represent data from the surface wash. 


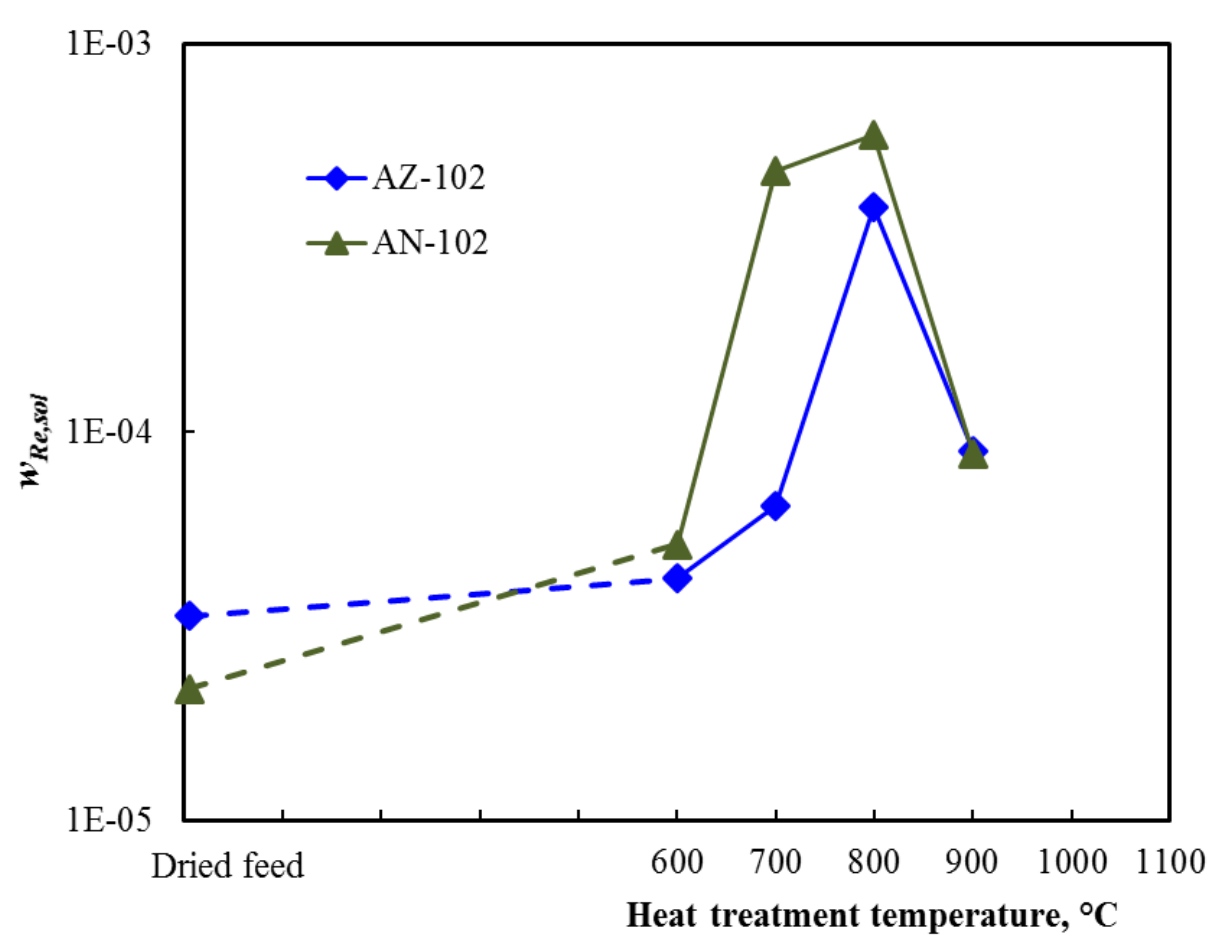

Figure 17. Mass fraction of Re in the soluble phase $\left(w_{R e, s o l}\right)$ of the dried feeds and heat-treated samples as a function of temperature (below detection limit at 1000 and $1100^{\circ} \mathrm{C}$ ).

Note that there is a significant difference in the slope of $F_{R e, s o l}$ versus temperature from the dried feed to the $600^{\circ} \mathrm{C}$ sample between the two feeds - the $F_{R e, s o l}$ in the $\mathrm{AZ}-102$ feed decreased faster (i.e., the Re in AZ-102 feed reacted faster). There is no difference between two feeds for the Re evolved as gas up to $600^{\circ} \mathrm{C}$, with only a small fraction of Re volatilized by $600^{\circ} \mathrm{C}$ for both feeds (Figure 15). This indicates that the Re in the soluble salt of the AZ-102 feed reacted and incorporated into the glass melt while a large fraction of Re in the $\mathrm{AN}-102$ feed still remained in the salt at $600^{\circ} \mathrm{C}$ as seen in Figure 16 and Figure 17. Note that the concentration of $\mathrm{Re}$ in the soluble phase reversed at $600^{\circ} \mathrm{C}$ compared to the dried feed,; that is, at $600^{\circ} \mathrm{C}, w_{R e, s o l}$ is larger for the $\mathrm{AN}-102$ feed although the mass fraction, $F_{\text {sol }}$, of the total soluble phase is higher for the AN-102 feed (see Figure 13). 
The mass fraction of $\mathrm{SO}_{3}$ and $\mathrm{Re}$ in the insoluble phase $\left(f_{\text {SO3,insol }}\right.$ and $\left.f_{R e \text {,insol }}\right)$ as a function of temperature are shown in Figure 18 and Figure 19, which are the overlays of the AN-102 and AZ-102 results for $f_{S O 3, \text { insol }}$ and $f_{\text {Re,insol }}$ given in Figure 8(c) and Figure 15 respectively. Figure 19 shows that, as pointed out earlier when Figure 15 was discussed, incorporation of Re was almost complete by approximately $700^{\circ} \mathrm{C}$ when the AZ-102 feed had a higher Re fraction incorporated to the insoluble (glass melt) than that of the $\mathrm{AN}-102$ feed and stayed that way up to $1100^{\circ} \mathrm{C}$. However, similar plots for $\mathrm{SO}_{3}$ in Figure 18 show that sulfate continues to incorporate into the melt at above $700^{\circ} \mathrm{C}$, and there is no difference in the fraction incorporated between the AN-102 and AZ-102 feeds, although the target concentration of $\mathrm{SO}_{3}$ in glass was approximately $20 \%$ different. In summary, at $\geq 800^{\circ} \mathrm{C}$, sulfate is the dominant salt component for both the AN-102 feed and the AZ-102 feed, and it contains the Re that has not incorporated into the glass melt. This sulfate salt rises to the melt surface $\geq 900^{\circ} \mathrm{C}$ where it continues to react with the glass melt and become incorporated into glass while the Re simply volatilizes without being incorporated into glass. 


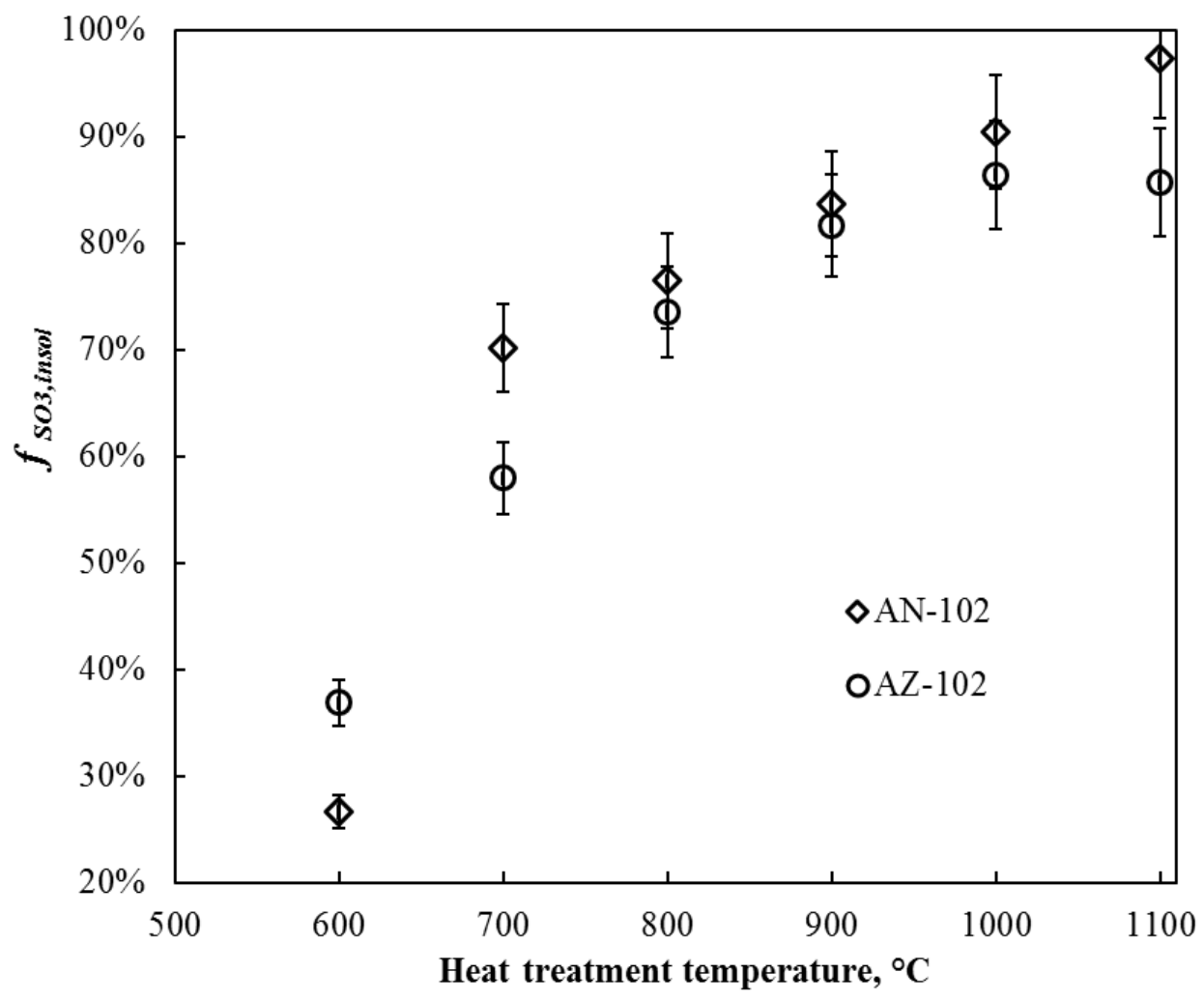

Figure 18. Mass fraction (in mass $\%)$ of $\mathrm{SO}_{3}$ in the insoluble phase $\left(f_{\text {SO3,insol }}\right)$ of the heat treated samples as a function of temperature. The error bars represent the standard deviation of chemical analyses. Note that these standard deviations do not include other uncertainties discussed in Section 3.4. 


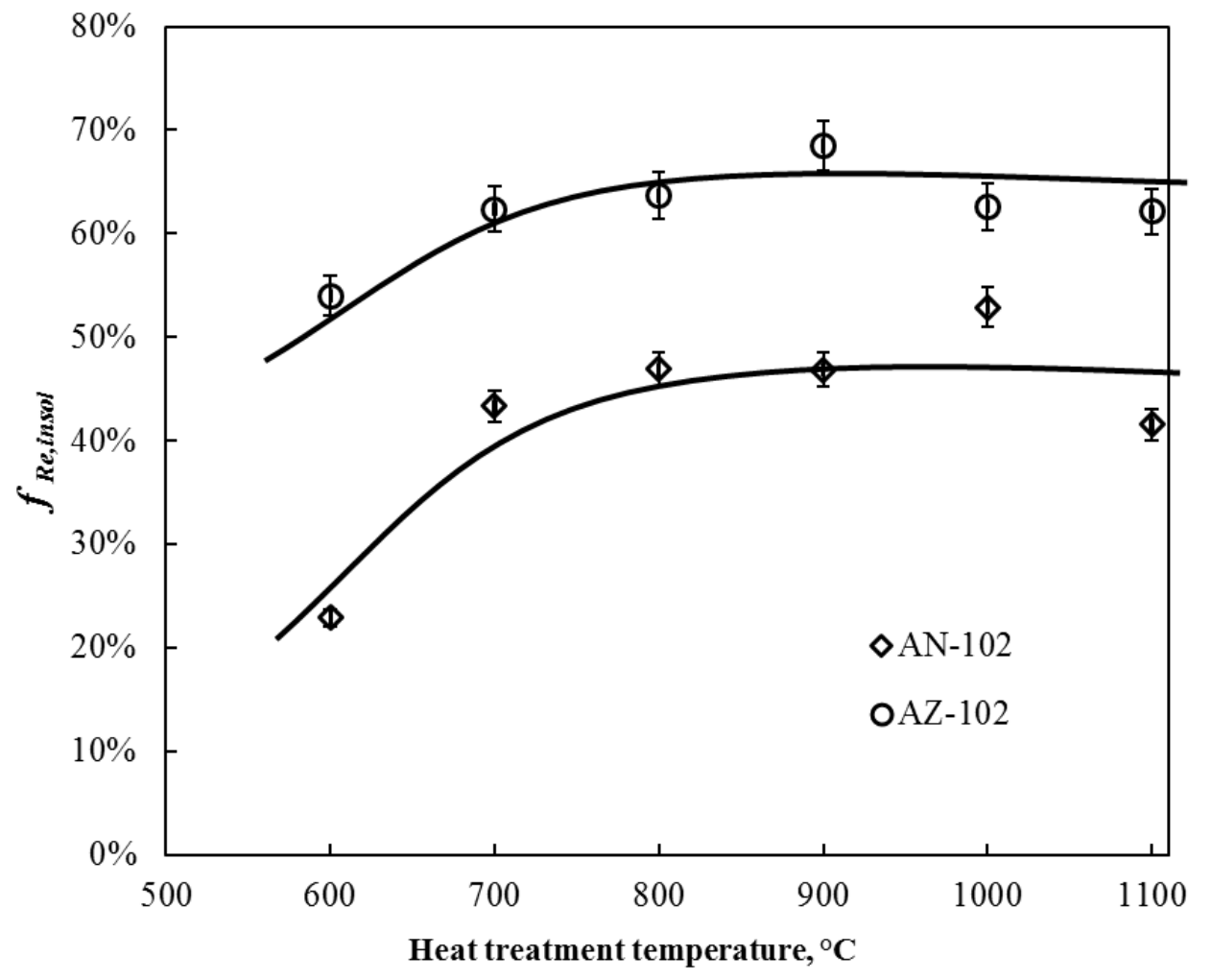

Figure 19. Mass fraction (in mass $\%)$ of $\operatorname{Re}$ in the insoluble phase $\left(f_{\text {SO3,insol }}\right)$ of the heat treated samples as a function of temperature (lines are for visual guidance). The error bars represent the standard deviation of chemical analyses.

As summarized in Table 4 and shown in Figure 19, Re retention $R_{R e}=f_{R e, \text { insol }}^{1100}$ by Eq. (10) is higher for the AZ-102 feed at $62.1 \%$ than for the AN-102 feed at $41.5 \%$. These $R_{R e}$ values are comparable to the average $f_{\text {Re,insol }}$ values of $63.9 \%$ for the AZ-102 feed and $46.3 \%$ for the AN-102 feed for the samples heat treated from 700 to $1100^{\circ} \mathrm{C}$, suggesting that there was no measurable volatilization from the glass melt $\geq 700^{\circ} \mathrm{C}$ as already discussed. From the scaled melter tests with the same feeds, $R_{R e}$ was $57 \%$ for the AZ-102 feed and 27\% for the AN-102 feed [12-14], which shows the same qualitative trend. It may be reasonable to assume that the factors affecting retention from crucible melts and scaled melter tests may overlap despite the significant differences in the processing conditions, especially the 
thermal history. Other differences include cold-cap formation in the scaled melter that helps to reduce the volatilization from melt surface by capturing a part of the volatiles coming from the glass melt below. However, the melter processing also includes air bubbling that may promote Re/Tc volatilization. To understand the primary reasons for higher Re retention in AZ-102 feeds compared to AN-102 feeds, the differences in feed and melting characteristics that can cause the difference in Re incorporation below $700^{\circ} \mathrm{C}$ are considered and discussed below.

First, the high-nitrate AN-102 feed evolves significantly more gases than the AZ-102 feed, which may contribute to the Re loss via the entrainment or carryover. The entrainment was suggested as a potential mechanism for the loss of some volatile components including Re from calcination studies with simulated high-level liquid wastes that are primarily nitrates [44]. However, this entrainment mechanism cannot explain the present results because there was little difference in the Re lost during melting at $\leq 700^{\circ} \mathrm{C}$ between $\mathrm{AN}-102$ and $\mathrm{AZ}-102$ feeds (Figure 15) considering that majority of gas evolution completed by $700^{\circ} \mathrm{C}$. That is, there was no difference in the Re that escaped the feed, but there was a significant difference in how much Re incorporated into glass at $\leq 700^{\circ} \mathrm{C}$.

Second, it is also possible that the vigorous gas generation from the high-nitrate AN-102 feed has an impact on Re incorporation reactions. However, this higher gas evolution from the AN-102 feed did not slow the reactions between the salt and other additive chemicals and minerals; overall the AN-102 feed reacted faster based on the results from XRD, mass loss, and chemical analyses. Therefore it is unlikely that the higher gas evolution from the AN-102 feed has a major impact on slow Re incorporation.

Third, the initial concentration of Re in the soluble phase of the AZ-102 feed, $w_{R e, s o l}^{0}$, is higher than in the AN-102 feed (Figure 17); that is, the soluble phase in the AZ-102 feed is more concentrated with Re, which would favor the faster Re incorporation initially if all other conditions were the same. However, this effect diminishes as the reaction progresses, resulting in the reversed Re concentration, $w_{R e, s o l}$, as long as the decreased rate of the total salt is comparable (Figure 13), which occurred before the 
feed reached $600^{\circ} \mathrm{C}$ as shown in Figure 17. Therefore, it is not this factor that has the primary effect on the different Re incorporation between the AN-102 and AZ-102 feeds.

Fourth, the composition of the soluble phase is different. As summarized in Table 9, the AN-102 salt is initially dominated by the alkali nitrates and alkali borates in the dried feed, whereas the dominant salt in the AZ-102 feed is alkali borates. By $600^{\circ} \mathrm{C}$, the $\mathrm{AN}-102$ feed contains primarily alkali nitrates and AZ-102 alkali borates. An explanation for the observed results of this study is that the Re mixed in a salt phase dominated by alkali borates incorporates better to the glass-forming melt during feed-to-glass conversion reactions than the Re in a salt with a high nitrate content. The importance of salt composition may also be stressed by the observation that the highly concentrated Re in the sulfate salt (high $w_{R e, s o l}$ ) did not incorporate into glass for both feeds; at $\geq 700^{\circ} \mathrm{C}$ for the $\mathrm{AN}-102$ feed and $\geq 800^{\circ} \mathrm{C}$ for the $\mathrm{AZ}-102$ while the sulfate, even the salt on the melter surface at $\geq 900^{\circ} \mathrm{C}$, continued to react with and incorporate into glass melt (Figure 18).

\subsection{Conclusions}

We investigated the behavior of Re (used as a surrogate for ${ }^{99} \mathrm{Tc}$ ) partitioning into different phases during crucible melting of two simulated Hanford LAW glass feeds (AN-102 and AZ-102). The present crucible melting tests with the AN-102 and AZ-102 feeds spiked with Re showed a qualitatively similar difference in Re retention to the results from the small-scale melter tests with ${ }^{99 \mathrm{~m}} \mathrm{Tc}$ and Re. We performed feed mass loss measurements, pellet tests for volume change, XRD analyses for crystalline phase evolution, and chemical analyses (after heat treatment and leaching) to identify the major factors that can cause a large difference in Re retention between these two feeds. We found that the incorporation of Re into glass melt virtually completed during the major feed-to-glass conversion reactions occurring at $\leq 700^{\circ} \mathrm{C}$ for both feeds. During this period, there was no difference between the two feeds in the amount

of Re that escaped, but there was a large difference in how much Re incorporated into the glass melt. The 
Re that still remained in the sulfate salt at $700^{\circ}$ eventually all volatilized from the salt without further incorporation into the melt for both feeds.

Our preliminarily conclusion is that the different compositions of the salt phase between these two feeds formed during the major feed-to-glass conversion reactions occurring at $\leq 700^{\circ} \mathrm{C}$ is responsible for the large difference in Re retention observed in both the scaled melter tests and the crucible melts. Specifically, Re in the salt of predominantly alkali borate in the AZ-102 feed incorporated more or faster into the glass-forming melt during feed-to-glass conversion reactions than Re in the salt of predominantly alkali nitrates in the AN-102 feed. However, details on how different salt compositions affect Re incorporation during feed-to-glass conversion reactions are not fully understood. Considering that the present study showed that the highest incorporation into glass melt occurred at $\leq 600^{\circ} \mathrm{C}$, our next studies will include the samples heat treated at lower temperatures (e.g., 400 and $500^{\circ} \mathrm{C}$ ). We also will apply modified leach procedures designed to overcome some difficulties identified in the present set of tests and will utilize any additional test methods and analytical techniques if necessary. Furthermore, we plan to perform more detailed studies to understand the effect of different salt composition using simplified feeds containing four to five of the most critical components to simulate the characteristics of each feed.

We also identified several reactions occurring during slurry preparation and drying. These reactions converted a set of crystalline phases to amorphous phases resulting in the evolution of water from hydrated chemicals and boric acid, as well as a small fraction of $\mathrm{CO}_{2}$ from carbonates. It can be postulated that these pre-melting reactions would affect the feed-to-glass conversion reactions at $\leq 700^{\circ} \mathrm{C}$, and possibly the incorporation of Re into glass melt. The set of tests performed in this study was not designed to provide the data needed for such direct connections. The planned studies using the simplified feeds mentioned above are expected to provide basic information that can be used to determine if such connections are possible. 


\section{Acknowledgements}

This work was supported by the U.S. Department of Energy's (DOE) Waste Treatment and Immobilization Plant Project of the Office of River Protection. The authors thank Jarrod Crum for X-ray diffraction quantitative analyses of crystalline phases, Dr. Pavel Hrma for helpful suggestions and discussions, and for Dr. Jaehun Chun for critical review of manuscript. Pacific Northwest National Laboratory (PNNL) is operated by Battelle Memorial Institute for DOE under contract DE-AC0576RL01830.

\section{References}

[1] Certa PJ, Empey PA (2011) River protection project system plan, ORP-11242, Rev. 6. Washington River Protection Solutions, Richland, WA. doi:10.2172/973951

[2] Ojovan MI, Lee WE (2011) Glassy Wasteforms for Nuclear Waste Immobilization. Metallurgical and materials transactions a-physical metallurgy and materials science 42A (4):837-851.

[3] Wilmarth WR, Lumetta GJ, Johnson ME, Poirier MR, Thompson MC, Suggs PC, Machara NP (2011) Review: Waste-pretreatment technologies for remediation of legacy defense nuclear wastes. Solvent Extraction and Ion Exchange 29 (1):1-48.

[4] Schonewill PP, Daniel RC, Russell RL, Shimskey RW, Burns CA, Billing JM, Rapko BM, Peterson RA (2012) Development of an S-saltcake simulant using crossflow filtration as a validation technique. Separation Science and Technology 47 (14-15):2098-2107.

[5] McGrail BP, Bacon DH, Icenhower JP, Mann FM, Puigh RJ, Schaef HT, Mattigod SV (2001) Near-field performance assessment for a low-activity waste glass disposal system: laboratory testing to modeling results. Journal of Nuclear Materials 298 (1-2):95-111.

[6] Mann F, Puigh R, Khaleel R, Finfrock S, McGrail B, Bacon D, Serne R (2003) Risk assessment supporting the decision on the initial selection of supplemental ILAW technologies, RPP-17675. CH2M Hill Hanford Group, Richland, WA. doi:10.2172/816325 
[7] Mann FM (2004) Annual summary of the integrated disposal facility performance assessment for 2004, DOE/ORP-2000-19, Rev. 4. CH2M Hill Hanford Group, Richland, WA. doi:10.2172/837629

[8] Wildung RE, Garland TR, McFadden KM, Cowan CE (1986) Technetium sorption in surface soils. In: Desmet G, Myttenaere C (eds) Technetium in the environment. Springer Netherlands, pp 115-129.

[9] Kaplan DI (2003) Influence of surface charge of an Fe-oxide and an organic matter dominated soil on iodide and pertechnetate sorption. Radiochimica Acta 91 (3):173-178.

[10] Um W, Chang H-S, Icenhower JP, Lukens WW, Serne RJ, Qafoku NP, Westsik JH, Jr., Buck EC, Smith SC (2011) Immobilization of 99-technetium (VII) by Fe(II)-goethite and limited reoxidation. Environmental Science \& Technology 45 (11):4904-4913.

[11] Um W, Chang H, Icenhower JP, Lukens WW, Serne RJ, Qafoku N, Kukkadapu RK, Westsik JH, Jr. (2012) Iron oxide waste form for stabilizing (TC)-T-99. Journal of Nuclear Materials 429 (1-3):201209.

[12] Pegg I (2015) Behavior of technetium in nuclear waste vitrification processes. J Radioanal Nucl Chem:1-6.

[13] Matlack KS, Muller IS, Pegg IL, Joseph I (2010) Improved technetium retention in Hanford LAW glass - Phase 1, VSL-10R1920-1. Vitreous State Laboratory, The Catholic University of America, Washington, DC.

[14] Matlack KS, Muller IS, Callow RA, D'Angelo N, Bardacki T, Joseph I, Pegg IL (2011) Improved technetium retention in Hanford LAW glass - Phase 2, VSL-10R2260-1. Vitreous State Laboratory, The Catholic University of America, Washington, DC.

[15] Muller I, Viragh C, Gan H, Matlack K, Pegg I (2009) Iron Mössbauer redox and relation to technetium retention during vitrification. In: Kuzmann E, Lázár K (eds) Proceedings of the International Symposium on the Industrial Applications of the Mössbauer Effect (ISIAME 2008). Springer Berlin Heidelberg, pp 347-354.

[16] Abramowitz H, Brandys M, Cecil R, D'Angelo N, Matlack KS, Muller IS, Pegg IL, Callow RA, Joseph I (2012) Technetium retention in WTP LAW glass with recycle flow-sheet DM10 melter testing, 
VSL-12R2640-1, Rev. 0. Vitreous State Laboratory, The Catholic University of America, Washington, DC. (http://www.osti.gov/scitech/biblio/1059435)

[17] Vienna JD, Kim D, Skorski DC, Matyas J (2014) Glass property models and constraints for estimating the glass to be produced at Hanford by implementing current advanced glass formulation efforts, PNNL-22631 (EWG-RPT-003), Rev. 1. Pacific Northwest National Laboratory, Richland, WA. (http://www.osti.gov/scitech/biblio/1170502)

[18] Pierce EM, Cantrell KJ, Westsik JH, Parker KE, Um W, Valenta MM, Serne RJ (2010) Secondary waste form screening test results — cast stone and alkali alumino-silicate geopolymer, PNNL-19505. Pacific Northwest National Laboratory, Richland, WA. doi:10.2172/989447

[19] Sundaram SK, Parker KE, Valenta MM, Pitman SG, Chun J, Chung C-W, Kimura ML, Burns CA, Um W, Westsik JH (2011) Secondary waste form development and optimization — cast stone, PNNL20159 Rev. 1. Pacific Northwest National Laboratory, Richland, WA. doi:10.2172/1027191

[20] Darab JG, Smith PA (1996) Chemistry of technetium and rhenium species during low-level radioactive waste vitrification. Chem Mater 8 (5):1004-1021.

[21] Kim D-S, Soderquist CZ, Icenhower JP, McGrail BP, Scheele RD, McNamara BK, Bagaasen LM, Schweiger MJ, Crum JV, Yeager JD, Matyas J, Darnell LP, Schaef HT, Owen AT, Kozelisky AE, Snow LA, Steele MJ (2005) Tc reductant chemistry and crucible melting studies with simulated Hanford lowactivity waste, PNNL-15131. Pacific Northwest National Laboratory, Richland, WA. doi:10.2172/15020035

[22] McKeown DA, Buechele AC, Lukens WW, Shuh DK, Pegg IL (2007) Tc and Re behavior in borosilicate waste glass vapor hydration tests. Environ Sci Technol 41:431-436.

[23] Lukens WW, McKeown DA, Buechele AC, Muller IS, Shuh DK, Pegg IL (2007) Dissimilar behavior of technetium and rhenium in borosilicate waste glass as determined by X-ray absorption spectroscopy. Chem Mater 19 (3):559-566.

[24] Buechele AC, McKeown DA, Lukens WW, Shuh DK, Pegg IL (2012) Tc and Re behavior in borosilicate waste glass vapor hydration tests II. Journal of Nuclear Materials 429 (1-3):159-165. 
[25] McCloy JS, Riley BJ, Goel A, Liezers M, Schweiger MJ, Rodriguez CP, Hrma P, Kim D-S (2012) Rhenium solubility in borosilicate nuclear waste glass: Implications for the processing and immobilization of technetium-99. Environmental Science \& Technology 46 (22):12616-12622.

[26] Soderquist CZ, Schweiger MJ, Kim D-S, Lukens WW, McCloy JS (2014) Redox-dependent solubility of technetium in low activity waste glass. Journal of Nuclear Materials 449 (1-3):173-180.

[27] Goel A, McCloy JS, Windisch CF, Jr, Riley BJ, Schweiger MJ, Rodriguez CP, and Ferreira JM (2013) Structure of rhenium-containing sodium borosilicate glass. International Journal of Applied Glass Science 4(1):42-52.

[28] Gassman PL, McCloy JS, Soderquist CZ and Schweiger MJ (2014) Raman analysis of perrhenate and pertechnetate in alkali salts and borosilicate glasses. J. Raman Spectrosc. 45: 139-147.

[29] Hrma P, Schweiger MJ, Humrickhouse CJ, Moody JA, Tate RM, Rainsdon TT, Tegrotenhuis NE, Arrigoni BM, Marcial J, Rodriguez CP, Tincher BH (2010) Effect of glass-batch makeup on the melting process. Ceramics-Silikaty 54 (3):193-211.

[30] Henager SH, Hrma P, Swearingen KJ, Schweiger MJ, Marcial J, TeGrotenhuis NE (2011) Conversion of batch to molten glass, I: Volume expansion. Journal of Non-Crystalline Solids 357 (3):829-835.

[31] Smith PA, Vienna JD, Hrma PR (1995) The effects of melting reactions on laboratory-scale waste vitrification. J Mater Res 10 (8):2137-2149.

[32] Darab JG, Meiers EM, Smith PA (1999) Behavior of simulated Hanford slurries during conversion to glass. In: Wronkiewicz DJ, Lee JH (eds) Scientific Basis for Nuclear Waste Management XXII, vol 556. Materials Research Society Symposium Proceedings. Boston, MA, pp 215-222.

[33] Hrma PR, Matyas J, Kim D-S (2002) The chemistry and physics of melter cold cap. In: Spectrum 2002: Exploring Science-Based Solutions and Technologies. 9th Biennial International Conference on Nuclear and Hazardous Waste Management, Reno, NV, August 4-8, 2002, American Nuclear Society, La Grange Park, IL. 
[34] Matyas J, Hrma P, Kim DS (2003) Analysis of feed melting procesess. In: Vienna JD, Spearing DR (eds) Environmental Issues and Waste Management Technologies in the Ceramic and Nuclear Industries IX: Ceramic Transactions, vol 155. American Ceramic Society, Nashville, TN, pp 69-78.

[35] Kim D-S, Bagaasen LM, Crum JV, Fluegel A, Gallegos A, Martinez B, Matyas J, Meyer PA, Paulsen DR, Riley BJ, Schweiger MJ, Stewart CW, Swoboda RG, Yeager JD (2006) Investigation of Tc migration mechanism during bulk vitrification process using Re surrogate, PNNL-16267. Pacific Northwest National Laboratory, Richland, WA. doi:10.2172/903263

[36] Hrma PR (2010) Retention of halogens in waste glass, PNNL-19361. Pacific Northwest National Laboratory, Richland, WA. doi:10.2172/981571

[37] Matlack KS, Muller IS, Gong WL, Pegg IL (2006) DuraMelter 100 Tests to Support LAW Glass Formulation Correlation Development, VSL-06R6480-1. Vitreous State Laboratory, The Catholic University of America, Washington, DC. doi:10.2172/1109494

[38] Vienna JD, Kim D-S, Muller IS, Piepel GF, Kruger AA (2014) Toward understanding the effect of low-activity waste glass composition on sulfur solubility. Journal of the American Ceramic Society 97 (10):3135-3142.

[39] Kim DS, Hrma P (1990) Volume changes during batch to glass conversion. American Ceramic Society Bulletin 69 (6):1039-1043.

[40] Li H, Hrma PR, Vienna JD (2000) Sulfate retention and segregation in simulated radioactive waste borosilicate glasses. In: Smith GL, Sundaram SK, Spearing DR (eds) Environmental issues and waste management technologies in the ceramic and nuclear industries VI: Ceramic Transactions, vol 119. American Ceramic Society, Westerville, OH, pp 237-246.

[41] Vienna JD, Hrma PR, Buchmiller WC, Ricklefs JS (2004) Preliminary investigation of sulfur loading in hanford law glass, PNNL-14649. Pacific Northwest National Laboratory, Richland, WA. doi:10.2172/893257

[42] Ebert WL (1995) The effects of the glass surface area/solution volume ratio on glass corrosion: A critical review, ANL-94/34. Argonne National Laboratory, Argonne, IL. doi:10.2172/67461 
[43] Hrma PR, Bagaasen LM, Beck AE, Brouns TM, Caldwell DD, Elliott ML, Matyas J, Minister KB, Schweiger MJ, Strachan DM, Tinsley BP, Hollenberg GW (2005) Bulk vitrification castable refractory block protection study, PNNL-15193. Pacific Northwest National Laboratory, Richland, WA. doi:10.2172/877052

[44] Igarashi H, Kato K, Takahashi T (1992) Effect of temperature on the entrainment of ruthenium, technetium and selenium in continuous calcination of simulated high-level liquid waste. Journal of Nuclear Science and Technology 29 (6):576-581. 